Key Words:

DWPF, noble metals, hydrogen, SRAT

Retention:

Permanent

\title{
DWPF CATALYTIC HYDROGEN GENERATION PROGRAM - REVIEW OF CURRENT STATUS
}

\author{
D. C. Koopman
}

JULY 2009

Savannah River National Laboratory

Savannah River Nuclear Solutions

Aiken, SC 29808

Prepared for the U.S. Department of Energy Under Contract Number DE-AC09-08SR22470

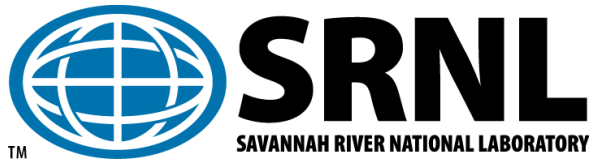




\section{DISCLAIMER}

This work was prepared under an agreement with and funded by the U.S. Government. Neither the U. S. Government or its employees, nor any of its contractors, subcontractors or their employees, makes any express or implied:

1. warranty or assumes any legal liability for the accuracy, completeness, or for the use or results of such use of any information, product, or process disclosed; or

2. representation that such use or results of such use would not infringe privately owned rights; or

3. endorsement or recommendation of any specifically identified commercial product, process, or service.

Any views and opinions of authors expressed in this work do not necessarily state or reflect those of the United States Government, or its contractors, or subcontractors.

Printed in the United States of America

Prepared for

U.S. Department of Energy 
Key Words:

DWPF, noble metals

Hydrogen, SRAT

Retention:

Permanent

\section{DWPF CATALYTIC HYDROGEN GENERATION PROGRAM - REVIEW OF CURRENT STATUS}

D. C. Koopman

JULY 2009

Savannah River National Laboratory

Savannah River Nuclear Solutions

Savannah River Site

Aiken, SC 29808

Prepared for the U.S. Department of Energy Under

Contract Number DE-AC09-08SR22470

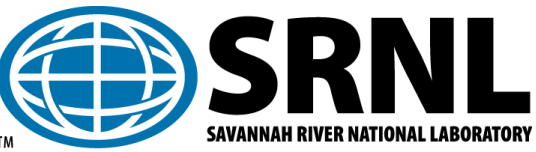




\section{REVIEWS AND APPROVALS}

D. C. Koopman, Process Technology Programs

Date

M. E. Stone, Peer Reviewer, Process Technology Programs

Date

S. H. Reboul, Peer Reviewer, Process Technology Programs

Date

C. C. Herman, Manager, Process Technology Programs

Date

S. L. Marra, Manager,

Date

Environmental \& Chemical Process Technology Research Programs

J. E. Occhipinti, Manager

Date

Waste Solidification Engineering 


\section{TABLE OF CONTENTS}

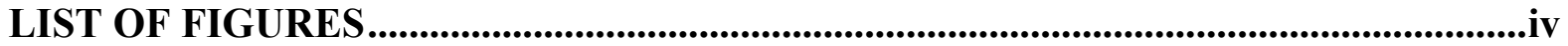

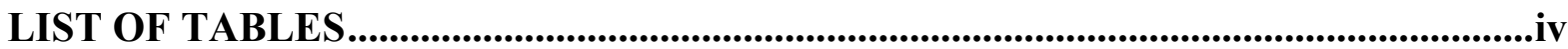

LIST OF ACRONYMS ....................................................................................................

1.0 Executive Summary..............................................................................................................1

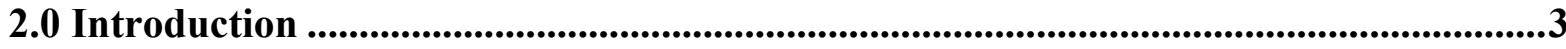

2.1 Previous Reviews of Catalytic Hydrogen Generation ..............................................3

2.1.1 External Review Panel...........................................................................................4

2.1.2 SRTC/SRNL Reviews .........................................................................................4

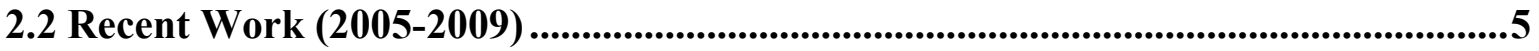

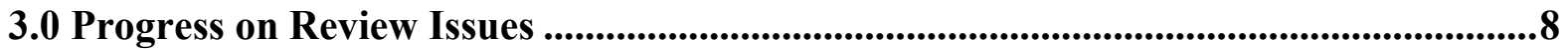

3.1 Status of 2002 CPC Hydrogen Review Issues.....................................................8

3.1.1 Established Points as of 2002 .............................................................................11

3.1.2 Potentially Contradictory Points as of 2002 ...........................................................15

3.1.3 Features Missing Conclusive Data as of 2002 ......................................................17

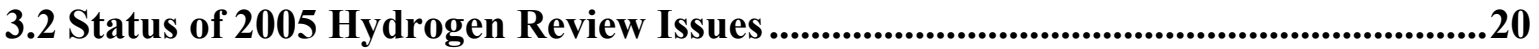

3.3 2005-2006 Simulant Findings ....................................................................................20

3.4 Recommendations Made by the Technical Review Panel ...........................................22

3.4.1 Near-term Recommendations ........................................................................23

3.4.2 Intermediate-term Recommendations .........................................................24

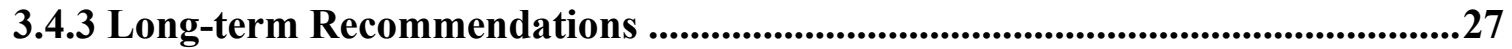

3.5 General Status of Catalytic Hydrogen Generation Program....................................28

4.0 Current Understanding of Hydrogen Generation .............................................................31

4.1 CPC Catalysis by Rhodium ..........................................................................................31

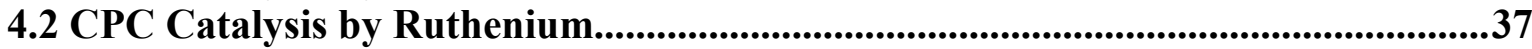

4.3 Determination and Control of Excess Acid.............................................................40

5.0 Conclusions ..................................................................................................................43

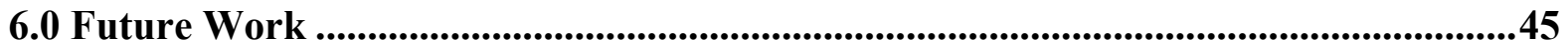

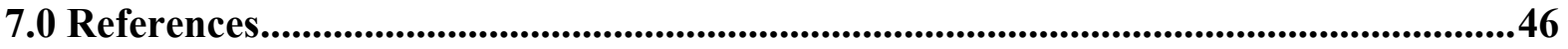




\section{LIST OF FIGURES}

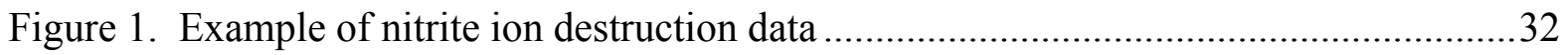

\section{LIST OF TABLES}

Table 1. Update on Established Points in the 2002 Review ................................................... 8

Table 2. Update on Issues with Apparently Contradictory Data in 2002 ..............................10

Table 3. Update on Issues with Insufficient Data in 2002 ..................................................10

Table 4. Noble Metal and Mercury Concentrations, wt \% in Dried Solids...............................17

Table 5. Status of Expert Panel Recommendations................................................................23 


\section{LIST OF ACRONYMS}

$\begin{array}{ll}\text { ACTL } & \text { Aiken County Technology Laboratory } \\ \text { AD } & \text { Analytical Development } \\ \text { CPC } & \text { Chemical Process Cell } \\ \text { DWPF } & \text { Defense Waste Processing Facility } \\ \text { E\&CPT } & \text { Environmental and Chemical Process Technology } \\ \text { FAVC } & \text { Formic Acid Vent Condenser } \\ \text { GC } & \text { Gas Chromatograph } \\ \text { HAN/FA } & \text { Hydroxyl amine nitrate/formic acid } \\ \text { IC } & \text { Ion Chromatography } \\ \text { ICP-AES } & \text { Inductively Coupled Plasma-Atomic Emission Spectroscopy } \\ \text { JMP } & \text { Commercial statistical software package used during analysis } \\ \text { LW/NA } & \text { Late wash/nitric acid } \\ \text { LWO } & \text { Liquid Waste Organization } \\ \text { MWWT } & \text { Mercury Water Wash Tank } \\ \text { PNNL } & \text { Pacific Northwest National Laboratory } \\ \text { PSAL } & \text { Process Science Analytical Laboratory } \\ \text { QA } & \text { Quality Assurance } \\ \text { SB } & \text { Sludge Batch } \\ \text { SME } & \text { Slurry Mix Evaporator } \\ \text { SRAT } & \text { Sludge Receipt and Adjustment Tank } \\ \text { SRNL } & \text { Savannah River National Laboratory } \\ \text { SRNS } & \text { Savannah River Nuclear Solutions, LLC } \\ \text { TR } & \text { Technical Report } \\ \text { TT\&QAP } & \text { Task Technical and Quality Assurance Plan } \\ \text { TTR } & \text { Task Technical Request } \\ \text { WSRC } & \text { Washington Savannah River Company } \\ \text { XAS } & \text { X-ray Absorption Spectroscopy } \\ & \end{array}$




\subsection{EXECUTIVE SUMMARY}

Significant progress has been made in the past two years in improving the understanding of acid consumption and catalytic hydrogen generation during the Defense Waste Processing Facility (DWPF) processing of waste sludges in the Sludge Receipt and Adjustment Tank (SRAT) and Slurry Mix Evaporator (SME). This report reviews issues listed in prior internal reviews, describes progress with respect to the recommendations made by the December 2006 external review panel, and presents a summary of the current understanding of catalytic hydrogen generation in the DWPF Chemical Process Cell (CPC).

Noble metals, such as $\mathrm{Pd}, \mathrm{Rh}$, and $\mathrm{Ru}$, are historically known catalysts for the conversion of formic acid into hydrogen and carbon dioxide. $\mathrm{Rh}, \mathrm{Ru}$, and $\mathrm{Pd}$ are present in the DWPF SRAT feed as by-products of thermal neutron fission of ${ }^{235} \mathrm{U}$ in the original waste. Rhodium appears to become most active for hydrogen as the nitrite ion concentration becomes low (within a factor of ten of the $\mathrm{Rh}$ concentration). Prior to hydrogen generation, $\mathrm{Rh}$ is definitely active for nitrite destruction to $\mathrm{N}_{2} \mathrm{O}$ and potentially active for nitrite to $\mathrm{NO}$ formation. These reactions are all consistent with the presence of a nitro-Rh complex catalyst, although definite proof for the existence of this complex during Savannah River Site (SRS) waste processing does not exist.

Ruthenium does not appear to become active for hydrogen generation until nitrite destruction is nearly complete (perhaps less nitrite than $\mathrm{Ru}$ in the system). Catalytic activity of $\mathrm{Ru}$ during nitrite destruction is significantly lower than that of either $\mathrm{Rh}$ or $\mathrm{Pd}$. $\mathrm{Ru}$ appears to start activating as $\mathrm{Rh}$ is deactivating from its maximum catalytic activity for hydrogen generation. The slow activation of the $\mathrm{Ru}$, as inferred from the slow rate of increase in hydrogen generation that occurs after initiation, may imply that some species (perhaps $\mathrm{Ru}$ itself) has some bound nitrite on it. $\mathrm{Ru}$, rather than $\mathrm{Rh}$, is primarily responsible for the hydrogen generation in the SME cycle when the hydrogen levels are high enough to be noteworthy.

Mercury has a role in catalytic hydrogen generation. Two potentially distinct roles have been identified. The most dramatic effect of $\mathrm{Hg}$ on hydrogen generation occurs between runs with and without any $\mathrm{Hg}$. When a small amount of $\mathrm{Hg}$ is present, it has a major inhibiting effect on $\mathrm{Rh}$-catalyzed $\mathrm{H}_{2}$ generation. The $\mathrm{Rh}-\mathrm{Ru}-\mathrm{Hg}$ matrix study showed that increasing mercury from 0.5 to $2.5 \mathrm{wt} \%$ in the SRAT receipt total solids did not improve the inhibiting effect significantly. The next most readily identified role for $\mathrm{Hg}$ is the impact it has on accelerating NO production from nitrite ion. This reaction shifts the time that the ideal concentration of nitrite relative to $\mathrm{Rh}$ occurs, and consequently causes the most active nitro-Rh species to form sooner. The potential consequences of this shift in timing are expected to be a function of other factors such as amount of excess acid, Rh concentration, etc.

Graphical data from the $\mathrm{Rh}-\mathrm{Ru}-\mathrm{Hg}$ study suggested that $\mathrm{Hg}$ might also be responsible for partially inhibiting Ru-catalysis initially, but that the inhibition was not sustained through the SRAT and SME cycles. Continued processing led to a subsequent increase in hydrogen 
generation that was often abrupt and that frequently more than doubled the hydrogen generation rate. This phenomenon may have been a function of the extent of $\mathrm{Hg}$ stripping versus the initial $\mathrm{Ru}$ concentration in these tests.

Palladium is an active catalyst, and activates during (or prior to) nitrite destruction to promote $\mathrm{N}_{2} \mathrm{O}$ formation followed by a very small amount of hydrogen. Pd then appears to deactivate. Data to date indicate that Pd should not be a species of primary concern relative to $\mathrm{Rh}$ and $\mathrm{Ru}$ for hydrogen generation. Pd was a very mild catalyst for hydrogen generation compared to $\mathrm{Rh}$ and $\mathrm{Ru}$ in the simulated waste system. Pd was comparable to $\mathrm{Rh}$ in enhancing $\mathrm{N}_{2} \mathrm{O}$ production when present at equal concentration. $\mathrm{Pd}$, however, is almost always present at less than a quarter of the Rh concentration in SRS sludge waste. Ag did not appear to ever become active for hydrogen generation. Data from two tests spiked with silver were comparable to the data from two tests with no noble metals.

All significant technical gaps and inconsistencies with historical data in the prior two internal reviews of catalytic hydrogen generation work at SRS have been resolved. About $90 \%$ of the recommended work from the external technical review panel has been completed. Work planned or in progress could bring progress on the review panel recommendations up to about $95 \%$ by the end of calendar 2009 . This primarily covers the sludge simulant matrix study on bulk compositional factors plus some follow-up work on X-ray absorption spectroscopy and improved acid equations. 


\subsection{INTRODUCTION}

Catalytic hydrogen generation is an issue in the DWPF Chemical Process Cell (CPC). The major CPC process equipment is air-purged to mitigate accumulation of potentially hazardous gases like hydrogen in the off-gas system and to prevent formation of flammable gas mixtures. DWPF attempts to avoid hydrogen generation rates in the SRAT and SME from exceeding $0.65 \mathrm{lbs} / \mathrm{hr}$ and $0.223 \mathrm{lbs} / \mathrm{hr}$ respectively. These correspond to $25 \%$ of the lower flammability limit at design purge rates. Hydrogen generation occurs during or after acidification of the waste sludge in the SRAT or SME once sufficient formic acid has been added. The combination of noble metals and excess formic acid has been identified as the major cause of catalytic hydrogen generation in DWPF. The catalytic hydrogen generation is in addition to that generated by radiolysis of water. Radiolysis is generally a small fraction of the SRAT and SME operating hydrogen limits.

The work presented in this technical report was originally identified as a result of Savannah River National Laboratory/Liquid Waste Organization (SRNL/LWO) meetings to define potential causes of catalytic hydrogen generation as well as from an external technical review panel commissioned to evaluate SRNL hydrogen related data and programs. ${ }^{1}$ The work scope was covered under the technical task request: HLW-DWPF-TTR-2007-0016. ${ }^{2}$ A task technical and quality assurance plan (TT\&QAP ${ }^{3}$ ) was drafted to address the needs of the TTR which included issues that were raised in meetings with LWO plus some of the recommendations made by the review panel.

This report has two main goals. The first is to describe progress on the issues raised in prior reviews of the catalytic hydrogen generation program. The second is to synthesize the experimental findings into a coherent summary of the present understanding of catalytic hydrogen generation. Background discussion of the three reviews is given in Section 2.1. Experimental work completed since 2005 is summarized in Section 2.2. A detailed update on each individual issue raised in two prior internal reviews of catalytic hydrogen generation in DWPF is given in Section 3.0, along with an update on progress that has been made on the recommendations from the external review panel.

The current understanding of catalytic hydrogen generation within the DWPF SRAT is presented in Section 4.0. The summary is a synthesis of the findings from past experimental and analytical work that have been documented in a series of technical reports and memos. The individual findings were integrated into an up to date perspective on the chemistry of catalytic hydrogen generation in DWPF. Conclusions are given in Section 5.0. A few potentially significant issues were identified as still unresolved. Plans to deal with these are given in Future Work, Section, 6.0.

\subsection{PREVIOUS REVIEWS OF CATALYTIC HYDROGEN GENERATION}

Three significant reviews of catalytic hydrogen generation in DWPF have been prepared in the past ten years. The first two were internal reviews prepared by SRTC/SRNL while the third was prepared by an external review panel of subject matter experts in the field of 
catalysis. Section 2.1 gives some background on the three reviews. Sections 3.1, 3.2, and 3.4 provide a complete update on the status of the individual issues and progress on the recommendations for future work.

\subsubsection{External Review Panel}

The most recent review was prepared by an external review panel that was convened in December 2006 to evaluate catalytic hydrogen generation issues at SRS. The panel was chaired by Dr. M. John Plodinec and included four other subject-matter experts with diverse backgrounds. A review summary report was received in March 2007. ${ }^{1}$ The review focused on the results of the Sludge Batch 4 (SB4) qualification SRAT/SME run in the Shielded Cells and the on-going SRNL program investigating catalytic hydrogen generation in DWPF.

The summary report from the panel included thirteen recommendations. One recommendation was that SRNL revisit the itemized inconsistencies and gaps in the historical DWPF-related catalytic hydrogen data that were identified in the two internal technical review reports $\left(2002^{4}, 2005^{5}\right)$. Progress on these issues is summarized in Section 3.4 of this report. There remains a relatively short list of open items, some of which are covered by projects already in progress.

\subsubsection{SRTC/SRNL Reviews}

The 2002 review report on catalytic hydrogen generation in $\mathrm{DWPF}^{4}$ divided the issues associated with catalytic hydrogen generation into three parts:

- Those points that were well established.

- Issues that were apparently contradicted by two or more sets of data.

- Potential issues that were not yet formally investigated or understood.

Some progress was made with respect to contradictory data and potentially unknown, but significant, factors between 2002 and 2005. The new findings were collected in the 2005 review $^{5}$, but many issues remained open.

Significant progress was made on most of the remaining unresolved issues in the period from 2005 to the present. The focus of the catalytic hydrogen generation program following the second internal review (or shortly before the SB4 Shielded Cells qualification SRAT/SME simulation in 2006) was on the impact of the form of noble metals (trimmed versus coprecipitated). ${ }^{6,7}$ Comparisons were performed using simulants that had either traditional trimmed noble metals (from adding solutions of $\mathrm{Pd}$ and $\mathrm{Rh}$ nitrate, solid $\mathrm{AgNO}_{3}$, and solid $\mathrm{RuCl}_{3}$ ) or coprecipitated noble metals (formed from soluble noble metal salts that were coprecipitated simultaneously with the bulk simulant solids during the $\mathrm{NaOH}$ strike).

Following the SB4 Shielded Cells qualification test and the external review panel visit, the focus of the hydrogen generation program shifted to emphasize some of the remaining issues that emerged as recommendations that came out of the external review. The new work included short term studies directly related to SB4, medium duration studies on the individual noble metals and mercury, including identifying issues related to catalyst activation, 
deactivation, and poisoning, and longer duration studies to better elucidate SRAT chemistry, acid consumption, the impact of bulk chemical species, etc.

\subsection{RECENT WORK (2005-2009)}

An accelerated program on improving the understanding of catalytic hydrogen generation and acid consumption in the DWPF Chemical Processing Cell (CPC) has produced considerable progress in the past several years. New stoichiometric acid equations are under development to better control excess acid in the Sludge Receipt and Adjustment Tank (SRAT). The multiple catalytic reactions of the individual noble metals have been better defined in general. The roles of mercury and nitrite ion in modifying the activity of the noble metal catalysts have also been investigated, and a better understanding of the roles of both species has emerged. The relationship between Slurry Mix Evaporator (SME) cycle hydrogen generation and SRAT cycle hydrogen generation is better understood.

A major factor that contributed to an improved understanding of noble metal catalysis in the DWPF SRAT cycle was the opportunity to complete a large number of different SRAT experiments with the same starting sludge simulant (ABC blend). These SRAT simulations occurred as part of various programs within SRNL such as the program to evaluate spherically beaded frit as an alternate to the current shard form, the program to identify alternative flowsheets and reductants for DWPF, and the catalytic hydrogen generation program. SRAT tests based on a single starting simulant were performed at multiple acid stoichiometries, with multiple noble metal concentration combinations, with and without mercury, and with alternative flowsheet concepts. Consequently, the composition and behavior of this simulant came to be well characterized.

The following list summarizes the principal tests performed or that are ongoing using the $\mathrm{ABC}$ blend simulant including references to the relevant summary documents:

- Four 4-L SRAT simulations at four different acid stoichiometries were performed at noble metal and mercury concentrations typical of recent sludge batches to find an appropriate acid stoichiometry for subsequent testing. These results along with a description of the $\mathrm{ABC}$ blend simulant preparation were documented in a memo. ${ }^{8}$

- $\quad$ Eight 22-L SRAT/SME simulations were performed with eight different noble metal concentration combinations and no mercury. These were followed by a second identical set of eight 22-L SRAT/SME simulations except for the substitution of spherically formed (bead) frit for regular frit in the SME cycle (the eight SRAT cases were run in duplicate). All tests were at a single acid stoichiometry. Individual noble metal concentrations were bounding for Savannah River Site wastes. The following work occurred as a consequence:

- A technical report summarizing noble metal dissolution data related to hydrogen generation was issued. ${ }^{9}$

- A technical report summarizing SRAT chemistry and acid consumption was issued. $^{10}$ 
- Two different 4-L SRAT simulations were performed in support of the above 22-L simulations matched to two of the eight cases, one with $0.2 \mathrm{wt} \% \mathrm{Rh}$ and one with $0.2 \mathrm{wt} \% \mathrm{Ru}$. The 4-L cases, however, had $1.5 \mathrm{wt} \%$ added $\mathrm{Hg}$. The $\mathrm{Ru}$ test was completed in time to be included in the initial technical reports. The $\mathrm{Rh}$ test was documented separately. ${ }^{11}$

- Select samples were sent to off-site national laboratories for analysis by X-ray absorption spectroscopy (XAS) to better characterize the noble metals and mercury speciation. A memo summarizing XAS analysis of $\mathrm{Ru}$ trimmed SRAT slurry samples with and without $\mathrm{Hg}$ was issued. ${ }^{12}$ Analysis of $\mathrm{Rh}$ samples is scheduled for 2009. This work is being performed by Pacific Northwest National Laboratory (PNNL).

- A statistically designed matrix of 4-L SRAT tests was completed to study the interactions between $\mathrm{Rh}, \mathrm{Ru}$, and $\mathrm{Hg}$. The acid stoichiometry and the $\mathrm{Ag}$ and $\mathrm{Pd}$ concentrations were held constant. Data from twelve preliminary process simulations (12 SRAT cycles, six with SME cycles) were documented in a technical report. ${ }^{13}$ Results of the statistical analysis of the final set of twelve SRAT simulations (ten of the preliminary simulations plus two supplemental simulations) have also been documented in a technical report. ${ }^{14}$

- A 4-L SRAT simulation was performed with sludge and trim compositions similar to the $\mathrm{Rh}-\mathrm{Ru}-\mathrm{Hg}$ matrix midpoint where the formic acid was replaced by an equivalent quantity of oxalic acid (in terms of equivalent moles of acidic protons). This run was part of the alternative flowsheet testing. A second 4-L SRAT simulation was performed where formic acid was nearly all replaced with nitric acid. These two runs were documented together in a memo. ${ }^{15}$

- A 4-L SRAT simulation was performed at the high $\mathrm{Rh}$, high $\mathrm{Ru}$, low $\mathrm{Hg}$ corner of the $\mathrm{Rh}-\mathrm{Ru}-\mathrm{Hg}$ matrix where a sodium nitrite solution was slowly added to the SRAT slurry following formic acid addition in an attempt to maintain a modest nitrite ion concentration to inhibit or deactivate the noble metal catalysts. This run was also part of the alternative flowsheet testing. The results of this test were documented in a memo. ${ }^{16}$

- The SRAT chemistry technical report proposed two alternative stoichiometric acid equations to the current DWPF equation. The new equations were similar in concept. One was intended to predict the minimum acid requirement for nitrite destruction, while the other was intended to predict a reasonable level of acid to accomplish full nitrite destruction and $\mathrm{Mn}$ reduction with a small excess for other reactions and to hold a lower $\mathrm{pH}$. The two new acid equations were compared to the current DWPF equation using the measured inputs from five recent Shielded Cells SRAT runs spanning Sludge Batch 1B to Sludge Batch 4. A memo summarizing the comparisons was issued. ${ }^{17}$ The new equation validation analysis has subsequently been extended to include two SB5 Shielded Cells runs, two sets of 9-10 SRAT runs in DWPF from SB4 and SB5, and a broader set of historical simulant results. The equations will also be evaluated during Sludge Batch 6 flowsheet simulation and qualification studies. 
- Work is planned to investigate the impact of SRAT heels on the new minimum acid equation inputs.

Additional data with other simulants became available through the testing performed in preparation for the Shielded Cells sludge batch qualification. Sludge Batch 5 (SB5) simulant tests were performed that matched the qualification composition in Tank 51 and the blend of Tank 51 with the SB4 heel in Tank 40. ${ }^{18}$ Several subsequent simulant tests were performed in an attempt to replicate foaminess seen during Shielded Cells testing. One pair of tests compared simulants with identical wt\% solids loadings but different rheological properties. The change in rheological properties was made by circulating some simulant through a high shear mixer. Shearing produced a significantly more viscous slurry by reducing the mean particle size. Although the morphology and total particle surface area were changed, the impact on hydrogen generation was minimal. ${ }^{19}$

A statistical evaluation was performed on the available hydrogen generation data through the SB4 Shielded Cells qualification simulation. ${ }^{20}$ This data review encountered statistical modeling issues like those found during the SB3 work on incorporating oxalate ion into the DWPF stoichiometric acid equation. ${ }^{21}$ The SB3 acid consumption modeling and the hydrogen generation rate modeling both found that many of the sludge composition variables in the available systems were highly correlated with other variables. This prevented establishing suspected primary factors as statistically significant and distinct from the background of all potential factors. As one example, the three individual noble metals (Pd, $\mathrm{Rh}$, and $\mathrm{Ru}$ ) were found to be extremely correlated, since they tended to be close to their predicted fission yield ratios in every sludge batch.

A second issue with statistical modeling was the presence of potentially significant factors that changed little in value within the database. The SRAT receipt Mn concentration in the solids was also found to be fairly constant, as was the reported slurry total inorganic carbon (TIC used for carbonate ion content). Both TIC and Mn were already known to be relevant to the calculation of the stoichiometric acid requirement for processing a batch in the SRAT. Because these two parameters were only varying slightly from test to test, however, the statistical analysis software did not find them useful in attempting to explain variations in behavior (acid consumption, hydrogen generation) from run to run. In other words, these two variables lacked "leverage" in the modeling. These two types of features in the historical data limited the usefulness of statistical approaches. These features also showed the need to perform the Rh-Ru-Hg and sludge simulant matrix studies which were designed to break correlations among suspected key variables and to force some of the fairly constant sludge compositional variables to span wider ranges of values. 


\subsection{PROGRESS ON REVIEW ISSUES}

Several independent projects of the DWPF catalytic hydrogen generation study have been completed over the seven years since the first internal review of catalytic hydrogen generation in 2002. This includes a study on $\mathrm{Hg}$ and air impacts in SB3, a study on the effects of coprecipitation and heat-treatment on the noble metals, a perturbation analysis of potential causes for the excess hydrogen in the SB4 qualification run, a statistical evaluation of hydrogen generation in the CPC, a single noble metal effects study, and the $\mathrm{Rh}-\mathrm{Ru}-\mathrm{Hg}$ matrix study. Fresh data on the potential impact of non-noble metal species on noble metal catalysis are anticipated from the sludge matrix tests in the next year.

This section reviews progress on understanding catalytic hydrogen generation. It is organized around the issues/recommendations that came out of the two internal and one external review documents. The issues from the 2002 internal review are discussed first, Section 3.1, followed by a discussion of several new issues raised in the 2005 internal review, Section 3.2. A brief status is given afterwards covering work performed from 20052006 between the last internal review and the external expert panel review, Section 3.3. The status of progress on the various short-term, mid-term, and long-term recommendations made by the external review panel is given in Section 3.4. Finally, Section 3.5 summarizes the recent work in the hydrogen program from 2007 to the present.

\subsection{STATUS OF 2002 CPC HYDROGEN REVIEW ISSUES}

The 2002 internal review of catalytic hydrogen generation produced a three-part list containing apparently well established points, potentially contradictory points, and possible gaps in the available data. ${ }^{4}$ Status on these three groups is summarized at a high level in Table 1 to Table 3. A more detailed discussion is presented in the subsequent sub-sections.

Table 1. Update on Established Points in the 2002 Review

\begin{tabular}{|c|c|c|c|}
\hline Issue & $\begin{array}{c}2002- \\
2009 \\
\text { data } \\
\text { confirm }\end{array}$ & $\begin{array}{c}\text { 2002- } \\
2009 \\
\text { data } \\
\text { contra- } \\
\text { dict }\end{array}$ & $\begin{array}{c}\text { 2002- } \\
2009 \\
\text { data } \\
\text { don't } \\
\text { address }\end{array}$ \\
\hline Noble metals catalyze hydrogen generation & $\mathrm{X}$ & & \\
\hline $\mathrm{Cu}$ and Ni may contribute to noble metal activity & & & $\mathrm{X}$ \\
\hline $\mathrm{Ag}$ interacts directly with $\mathrm{Rh}, \mathrm{Ru}$, and $\mathrm{Pd}$ & & $\mathrm{X}$ & \\
\hline $\mathrm{Hg}$ interacts directly with $\mathrm{Rh}, \mathrm{Ru}$, and $\mathrm{Pd}$ & & $\mathrm{X}$ & \\
\hline Nitrite ion plays a role in noble metal activity & $\mathrm{X}$ & & \\
\hline Hydrogen generation is not $\mathrm{pH}$ limited & $\mathrm{X}$ & & \\
\hline Excess acid relates directly to hydrogen generation & $\mathrm{X}$ & & \\
\hline $\mathrm{Pd}$ is less active than $\mathrm{Rh}$ or $\mathrm{Ru}$ & $\mathrm{X}$ & & \\
\hline
\end{tabular}


Table 1 - continued

\begin{tabular}{|l|c|c|c|}
\hline Issue & $\begin{array}{c}2002- \\
2009 \\
\text { data } \\
\text { confirm }\end{array}$ & $\begin{array}{c}2002- \\
2009 \\
\text { data } \\
\text { contra- } \\
\text { dict }\end{array}$ & $\begin{array}{c}2002- \\
2009 \\
\text { data } \\
\text { don't } \\
\text { address }\end{array}$ \\
\hline Rh activates more readily than $\mathrm{Ru}$ & $\mathrm{X}$ & & \\
\hline Rh activity is enhanced by Fe precipitate & & & $\mathrm{X}$ \\
\hline Rh activity is enhanced by hydrous Al precipitate & & & $\mathrm{X}$ \\
\hline Noble metals do not sustain maximum activity & $\mathrm{X}$ & & \\
\hline $\mathrm{Cu}$ contributes to hydrogen at low noble metal levels & & & $\mathrm{X}$ \\
\hline $\mathrm{N}_{2} \mathrm{O}$ generation generally precedes $\mathrm{H}_{2}$ generation & $\mathrm{X}$ & & \\
\hline $\mathrm{H}_{2}$ generation may be sensitive to equipment scale & $\mathrm{X}$ & & \\
\hline Nitric acid/late wash is better than formic acid/HAN & & & $\mathrm{X}$ \\
\hline Formic acid makes $\mathrm{H}_{2}$ and $\mathrm{CO}_{2}$ over $\mathrm{H}_{2} \mathrm{O}$ and $\mathrm{CO}$ & $\mathrm{X}$ & & \\
\hline Formaldehyde and methyl formate are poisons & & & $\mathrm{X}$ \\
\hline Higher carbonate may inhibit noble metal activation & & & $\mathrm{X}$ \\
\hline NTA and EDTA are catalyst poisons & & & $\mathrm{X}$ \\
\hline SB1 A, SB1B, and $\mathrm{SB} 2$ understate the potential for $\mathrm{H}_{2}$ & $\mathrm{X}$ & & \\
\hline Flowsheet modifications mitigated $\mathrm{H}_{2}$ generation & & & $\mathrm{X}$ \\
\hline SME cycle $\mathrm{H}_{2}$ depends on SRAT cycle and SME options & $\mathrm{X}$ & & \\
\hline Slower activation and slower deactivation correlate & $\mathrm{X}$ & & \\
\hline
\end{tabular}

Only limited contradictory data were obtained since 2002 on the 24 apparently established points as of the 2002 review. These were more of a refinement, or somewhat altered perspective, on what was believed to be known in 2002 . 
Table 2. Update on Issues with Apparently Contradictory Data in 2002

\begin{tabular}{|c|c|c|}
\hline Issue & $\begin{array}{c}\text { 2002-2009 } \\
\text { data } \\
\text { support }\end{array}$ & $\begin{array}{c}2002-2009 \\
\text { data don't } \\
\text { support } \\
\end{array}$ \\
\hline Mercury is a noble metal poison & $\mathrm{X}$ & \\
\hline Mercury promotes increased activity & & $\mathrm{X}$ \\
\hline $\mathrm{Rh}$ is inactive in the presence of nitrite ion & & $\mathrm{X}$ \\
\hline $\mathrm{Rh}$ is active with or without nitrite ion & $\mathrm{X}$ & \\
\hline $\mathrm{Ru}$ is inactive in sludge simulants & & $\mathrm{X}$ \\
\hline $\mathrm{Ru}$ is active in sludge simulants & $\mathrm{X}$ & \\
\hline $\mathrm{Ru}$ is only active in the absence of nitrite ion & $\mathrm{X}$ & \\
\hline $\mathrm{Pd}$ is below its fission yield relative to $\mathrm{Rh}$ and $\mathrm{Ru}$ & $\mathrm{X}$ & \\
\hline Pd is above its fission yield in HM waste & & $\mathrm{X}$ \\
\hline $\mathrm{Rh}$ is a homogeneous catalyst & $\bar{X}$ & \\
\hline $\mathrm{Rh}$ is a heterogeneous catalyst & $\mathrm{X}$ & \\
\hline Activity goes as $\mathrm{Ru}>\mathrm{Pd}>\mathrm{Rh}$ & & $\mathrm{X}$ \\
\hline Activity goes as $\mathrm{Pd}>\mathrm{Rh}>\mathrm{Ru}$ & & $\mathrm{X}$ \\
\hline Activity goes as $\mathrm{Rh}>\mathrm{Ru}>\mathrm{Pd}$ & $\bar{X}$ & \\
\hline
\end{tabular}

Generally, all of the contradictory issues have been resolved, although the most active form of $\mathrm{Rh}$ may be a complex that is bound to the insoluble solids and/or in free solution.

Table 3. Update on Issues with Insufficient Data in 2002

\begin{tabular}{|l|c|c|c|}
\hline Issue & $\begin{array}{c}2002- \\
2009 \\
\text { data } \\
\text { clarify }\end{array}$ & $\begin{array}{c}2002- \\
2009 \\
\text { data } \\
\text { don't } \\
\text { clarify }\end{array}$ & $\begin{array}{c}\text { Issue has } \\
\text { lost } \\
\text { relevance }\end{array}$ \\
\hline Oxygen impacts $\mathrm{H}_{2}$ generation & & $\mathrm{X}$ \\
\hline Mixing intensity impacts $\mathrm{H}_{2}$ generation & $\mathrm{X}$ & & \\
\hline The pH and/or solution potential relates to $\mathrm{H}_{2}$ & $\mathrm{X}$ & & \\
\hline Rh and Ru could activate simultaneously & $\mathrm{X}$ & & \\
\hline The bulk sludge solids could impact noble metals & & $\mathrm{X}$ & \\
\hline The supernate anions could impact noble metal activity & & $\mathrm{X}$ & \\
\hline Ag-noble metal alloys might alter catalytic activity & $\mathrm{X}$ & & $\mathrm{X}$ \\
\hline
\end{tabular}

Generally, significant progress has been made in understanding all three areas discussed in the 2002 review. Progress on the individual issues from the three groups is discussed in detail below. A brief commentary follows each point concerning new, supplemental, and/or contradictory data that have been obtained in the 2002-2009 period. This is followed by the available resolution/confirmation as of early 2009 . 


\subsubsection{Established Points as of 2002}

Listed below are the 24 original points that were considered well documented and not contradicted by the available data as of the 2002 review. The original points are reprinted verbatim in italics. A brief summary of any significant new information follows each point.

1) Noble metals catalyze the decomposition of formic acid to produce hydrogen.

- $\quad R h, R u$, and Pd are present in HLW as fission products and are known catalysts for this reaction.

- $\quad$ Ru:Rh:Pd are expected to be present at ratios of about 3.75:1.0:0.52 by fission yield.

- $\quad$ Ag is present from natural sources.

- $\quad$ Pt, Ir, Os, and Au are not ${ }^{235} U$ fission products, and should not be in SRS waste.

- Negligible hydrogen generation is detected in SRAT runs without noble metals.

No contradictory data have been obtained.

2) Elemental copper and nickel are potential additions to the formic acid decomposition catalyst list, but:

- Copper may be irrelevant at the low concentrations seen in sludge-only processing today, and may remain of small consequence depending on the final design of the new Salt Waste Processing Facility.

- $\quad$ Nickel is probably not reduced to elemental form during SRAT processing.

No contradictory data have been obtained. In addition, processing data shows negligible dissolution of insoluble copper species during SRAT processing. Some Ni dissolution is observed, but there is no evidence that a metallic phase ever forms. Salt waste processing is no longer expected to bring in significant copper.

3) Silver can interact directly with $R h, R u$, and $P d$.

- $\quad$ Silver alloys with the noble metals seem to have lower activity than systems containing noble metals without silver.

No contradictory data have been obtained. Data have been obtained, however, that indicate the insoluble silver species in simulant waste does not dissolve during SRAT processing, and that it has negligible intrinsic catalytic activity for hydrogen generation. Alloy formation is not indicated. Therefore, the impact of silver on the $\mathrm{Rh}, \mathrm{Ru}$, and Pd should be negligible.

4) Mercury can interact with noble metals.

- $\quad H g$ can form amalgams (liquid alloys) with noble metals.

- $\quad H g$ apparently impacts the catalytic activity of noble metals.

A refined perspective on the role of mercury has evolved. Data indicate that a small amount of mercury (potentially less than a few tenths of a wt\% in the total solids) produces most of the inhibiting effect seen. XAS data do not support a metallic form of $\mathrm{Ru}$ (Rh data are 
expected in the next year). $\mathrm{Ru}-\mathrm{Hg}$ data did not conclusively indicate any amalgam, but did confirm that $\mathrm{Hg}$ reduces to the element before the end of acid addition. $\mathrm{Hg}$ does appear to alter nitrite destruction chemistry in the presence of $\mathrm{Rh}$ and/or $\mathrm{Ru}$, but whether this is accomplished by metallic $\mathrm{Hg}$ on its own or in concert with other noble metals is not known. By impacting nitrite, $\mathrm{Hg}$ indirectly impacts the $\mathrm{Rh}$ and $\mathrm{Ru}$ catalysis which are themselves directly impacted by nitrite ion concentration. There may also be an impact from stripping $\mathrm{Hg}$, since many SRAT/SME simulations show an abrupt increase in hydrogen generation during boiling long after the initial surge due to Rh has come and gone; that is, $\mathrm{Hg}$ may fall below the effective inhibiting concentration for Ru due to steam stripping.

5) The nitrite ion plays a role in noble metal catalytic activity.

- $\quad$ Delaying nitrite destruction delays the peak hydrogen generation rate.

- $\quad$ Overly delaying nitrite destruction creates the potential for excessive SME cycle hydrogen.

- $\quad$ Lack of nitrite in the feed leads to less hydrogen generation.

These findings are consistent with the discussion about the current understanding of $\mathrm{Rh}$ and $\mathrm{Ru}$ catalysis given in Sections 4.1 and 4.2. As noted in 4), Hg impacts nitrite destruction. Considerable supporting data have been obtained.

6) Hydrogen can be generated over a wide range in $\mathrm{pH}$, perhaps from $\sim 8$ on down.

No contradictory data, and much supporting data, have been obtained. New data also show hydrogen generation at $\mathrm{pH}$ values above eight.

7) The amount of acid added directly relates to hydrogen generation in the SRAT.

- More total acid gives more total hydrogen.

- Hydrogen is not evolved during nitric acid addition to waste sludge, except from radiolysis.

- $\quad$ More hydrogen is produced when more formic acid is added.

- Additional hydrogen is produced when supplemental additions of nitric acid are made to neutralized sludge containing formate/formic acid.

- Bench-scale simulations of a formic acid tank dump show that the hydrogen generation rate can approach the DWPF design basis for the SRAT, $0.65 \mathrm{lb} / \mathrm{hr}$, with relatively low concentrations of noble metals (Tank 42).

The above viewpoint has been refined somewhat. The current understanding is that the above trends define the limiting behaviors of the SRAT system as these individual parameters are adjusted to extremely high or low values. In intermediate processing regions, such as moderate excess acid with SB3-SB5 levels of noble metals, the non-linear response of the hydrogen generation rate to changing conditions could locally reverse some of the trends. In other words, the peak hydrogen generation rate might increase somewhat with a decrease in excess acid, or might increase somewhat with a decrease in Rh concentration. 
8) Palladium is the least active of the three noble metals in sludge simulant testing. Palladium was essentially inactive in HM and Purex sludge simulants.

Confirmation was provided by the sixteen 22-L bead-frit runs in the context of hydrogen generation, which included two runs with $0.2 \mathrm{wt} \% \mathrm{Pd}$. $\mathrm{Pd}$ was active during nitrite destruction, however, more $\mathrm{N}_{2} \mathrm{O}$ formation and more total off-gas was generated than in matching runs with no noble metals. Therefore, $\mathrm{Pd}$ is not "essentially inactive" in a broad catalytic sense, but has only limited activity for producing hydrogen at SRS concentrations with the current DWPF flowsheet.

9) Rhodium appears to activate more readily than ruthenium, i.e. Rh begins to produce hydrogen sooner in time than Ru under identical conditions. Ru is more active than $R h$ in the absence of nitrite.

$\mathrm{Rh}$ apparently is most active for hydrogen generation when a small amount of nitrite remains, while $\mathrm{Ru}$ does not activate for hydrogen generation until essentially all nitrite is destroyed, so this point is confirmed and clarified. This is discussed in more detail in Sections 4.1 and 4.2. $\mathrm{Rh}$ is also active during nitrite destruction in promoting $\mathrm{N}_{2} \mathrm{O}$ formation. After nitrite destruction, $\mathrm{Ru}$ seems to become more active than $\mathrm{Rh}$.

10) Rh activity is enhanced by the presence of the iron precipitate.

11) Rh activity is enhanced by the presence of hydrous aluminum oxide.

No contradictory experimental data have been obtained. Statistical modeling work, however, did not identify these trends as significant.

12) Processes are at work that tend to decrease the activity of the noble metals over time, however one noble metal can become active after another has lost most of its activity.

No contradictory data and much supporting data have been obtained. Rh does appear to activate for hydrogen generation before $\mathrm{Ru}$. Both $\mathrm{Rh}$ and $\mathrm{Ru}$ undergo dissolution periods and precipitation periods during SRAT processing.

13) Copper appeared to contribute to hydrogen generation in runs with low levels of noble metals.

No contradictory data have been obtained; however two tests with copper and no noble metals produced no measurable hydrogen.

\section{4) Hydrogen generation is normally preceded by $\mathrm{N}_{2} \mathrm{O}$ generation in waste sludge tests.}

Considerable supporting data have been obtained. $\mathrm{N}_{2} \mathrm{O}$ generation correlates with nitrite destruction which generally precedes significant hydrogen generation. 
15) Hydrogen generation may be sensitive to experimental scale (equipment selection and operation).

Hydrogen generation is sensitive to many things. The precision of replicate runs in producing the same hydrogen generation rate profiles is only fair (perhaps $\pm 30 \%$ about a mean profile as a preliminary estimate based on replicate trials in the bead-frit and $\mathrm{Rh}-\mathrm{Ru}-\mathrm{Hg}$ studies). The time dependence of the hydrogen generation reaction is reproduced more accurately than the magnitude of the hydrogen generation rate. Variations in hydrogen generation rate magnitude reproducibility have been examined. Only a fraction of the variation can be attributed to possible issues with control of the internal He standard or calibration of the GC's.

16) Switching to the Nitric Acid/Late Wash flowsheet led to a reduction in hydrogen generation compared to the Formic Acid/HAN flowsheet.

No contradictory data have been obtained. The point has lost relevance since neither salt waste processing option was pursued long term.

17) Hydrogen and carbon dioxide are the primary products in simple systems. Other products include carbon monoxide and water. CO has only rarely been detected in SRAT cycles at any significant concentration.

This point is in reference to the catalytic decomposition of formic acid. Considerable supporting data for the absence of significant carbon monoxide have been obtained (CO elutes between $\mathrm{N}_{2}$ and $\mathrm{NO}$ on the A column of the lab-scale gas chromatographs and a peak in this location is almost never seen). The molar production rate of $\mathrm{CO}_{2}$ generally exceeds that of $\mathrm{H}_{2}$ during the period of catalytic hydrogen generation, indicating that other reactions are occurring (either producing additional $\mathrm{CO}_{2}$ or consuming some of the $\mathrm{H}_{2}$ ).

18) Formaldehyde and methyl formate are possible catalyst poisons.

This point was not studied at SRS since the initial review.

19) Increased carbonate content may correlate with longer induction periods for noble metal activation.

The accurate determination of the initial slurry carbonate content by measurement of total inorganic carbon has been identified as a major source of uncertainty in modeling the stoichiometric acid requirement. SRAT data sets, however, indicate that the carbonate in the starting sludge is converted to $\mathrm{CO}_{2}$ before significant nitrite destruction, and thus before noble metal catalyst activation for hydrogen generation. Any delay in hydrogen generation due to carbonate would be the delay to add the additional acid needed to destroy it prior to nitrite destruction. 
20) The complexing agents NTA (nitrilotriacetic acid) and EDTA (ethylene diamine tetraacetic acid) are catalyst poisons. EDTA may prevent ruthenium precipitation.

This point has not been studied at SRS since the University of Georgia testing that identified these two species as potential catalyst poisons in 1992.

21) Shielded Cells tests with real sludges prior to DWPF start-up indicate that hydrogen generation can be much higher (>100 time larger) than what was seen in the first three Shielded Cell qualifications runs for Sludge Batches $1 A, 1 B$, and 2.

Significant hydrogen ( $>10 \%$ of the DWPF processing limits) was produced during Sludge Batch 4 and Sludge Batch 5 qualification testing in the Shielded Cells.

22) Flowsheet modifications (HAN/FA to LW/NA to sludge-only with Cu to sludge-only without $\mathrm{Cu}$ ) appear to have had a net mitigating effect on peak hydrogen generation.

This point was not studied further, since there are no plans to convert back to the HAN/FA flowsheet. Nothing has emerged to question the original conclusion.

23) SME cycle hydrogen generation depends on SRAT product nitrite, additional frit acid, and hydrogen generation rate at the end of the SRAT cycle in addition to the levels of noble metals.

The role of nitrite in setting the active catalyst species is discussed in Section 4.0. The newer data are consistent with this point.

24) Delaying catalyst activation (extending the induction period) seems to correlate with sustained catalytic activity (extended and slower deactivation).

This point appears to be supported by the newer data. Delaying catalyst activation, however, appears to be accomplished by slowing nitrite destruction, which occurs when less total acid and/or less total formic acid are added to the SRAT. Less total acid correlates to less excess acid which generally correlates to a reduced maximum hydrogen generation rate. The maximum generation rate is more important to DWPF than how long it is sustained.

\subsubsection{Potentially Contradictory Points as of $\mathbf{2 0 0 2}$}

The factors in this section had limited available experimental data in 2002. The available data appeared to be contradictory as to the effect of a certain factor on catalytic hydrogen generation. The six original 2002 points, reprinted verbatim in italics below, listed the apparent contradictions ${ }^{4}$. It was speculated in 2002 that: In some cases both (all) statements in a group may somehow be true, but the statements may be limited to certain specific instances that do not permit generalization. The six instances of contradictory data have all become better understood in the past seven years. An updated commentary follows each of the six points below. 
1) Mercury is a noble metal catalyst poison. Mercury is a promoter of increased activity.

No data have been obtained to indicate that mercury is a promoter of increased catalytic hydrogen generation activity per se. The absence of mercury has been found to lead to higher hydrogen generation rates. ${ }^{22,23}$ Data have been obtained that indicate that $\mathrm{Hg}$ does alter the balance of the competing nitrite destruction reactions and generally accelerates nitrite destruction overall, i.e. mercury appears to be promoting nitrite destruction. ${ }^{10}$ Nitrite concentration is very significant to $\mathrm{Rh}$ and $\mathrm{Ru}$ catalytic hydrogen generation. It is quite likely that a run has been performed where the presence of mercury shifted the timing of maximum catalytic activity of a nitro-rhodium complex in such a manner as to produce an increase in hydrogen generation. It is also possible that issues with quantitative reproducibility of hydrogen generation profiles may have led to a false finding in relatively similar tests.

2) Rhodium is inactive in the absence of nitrite ion. Rhodium is active with or without nitrite ion.

Rhodium is catalytically active for nitrite destruction, but not hydrogen generation, when nitrite concentrations are high. Rh appears to achieve its maximum catalytic activity for hydrogen generation when nitrite ion concentrations are low but nonzero. Rh loses much of its catalytic activity for hydrogen generation when nitrite ion is essentially totally eliminated. ${ }^{9,10}$

3) Ruthenium is not active in sludge simulants. Ruthenium is active in sludge simulants. Ruthenium is only active in the absence of nitrite ion.

$\mathrm{Ru}$ is definitely catalytically active for hydrogen generation during sludge simulant processing, but $\mathrm{Ru}$ appears to become active for hydrogen generation when the nitrite ion concentration falls below the $\mathrm{Ru}$ concentration, i.e. when nitrite ion is essentially totally destroyed or "absent". 9,10

4) The fission yield gives $R u$ to $R h$ to $P d$ in the ratio of 3.75 to 1.0 to 0.52 . The HM noble metal basis has the ratios as 5.7 to 1.0 to 2.1. The Purex noble metal basis has the ratios as 3.5 to 1.0 to 3.25. Pd is preferentially removed during tank farm operations (precipitation, decanting, and washing) compared to $R h$ and $R u$. It is typically present below the fission yield relative to $R h$.

No supporting data have been obtained on real waste sludges in the past seven years to justify an enhanced basis for Pd relative to Rh in either Purex or HM sludges. Pd has typically been measured at concentrations below the expected slow ${ }^{235} \mathrm{U}$ neutron fission yield relative to Rh in sludge batch qualification samples, ${ }^{24}$ that is, $\mathrm{Pd} / \mathrm{Rh}$ is typically less than 0.52 and not near 2.1-3.25. This is consistent with preferential removal of soluble Pd from sludge waste tanks during tank supernate transfers. Noble metal and mercury analytical results for the first six sludge batch qualification samples are given in Table 4. 
SRNL-STI-2009-00214, REVISION 0

Table 4. Noble Metal and Mercury Concentrations, wt\% in Dried Solids

\begin{tabular}{|l|l|l|l|l|l|}
\hline & $\mathrm{Ag}$ & $\mathrm{Pd}$ & $\mathrm{Rh}$ & $\mathrm{Ru}$ & $\mathrm{Hg}$ \\
\hline SB1A & 0.014 & 0.0060 & 0.00075 & 0.00281 & 0.16 \\
\hline SB1B & 0.036 & 0.0021 & 0.0051 & 0.021 & 1.26 \\
\hline SB2 & 0.0106 & 0.00089 & 0.00777 & 0.0332 & 0.195 \\
\hline SB3 & 0.0115 & 0.00166 & 0.00712 & 0.0362 & 0.065 \\
\hline SB4 & 0.00292 & 0.00086 & 0.0104 & 0.0427 & 2.52 \\
\hline SB5 & 0.0135 & 0.00403 & 0.025 & 0.110 & 2.22 \\
\hline
\end{tabular}

Data were originally taken from the six individual qualification sample reports and subsequently compiled for this review. ${ }^{25,26} \mathrm{Ru} / \mathrm{Rh}$ has been about four (close to 3.75) as expected, while $\mathrm{Rh} / \mathrm{Pd}$ has been less than 0.4 since SB1B.

5) Rh is a homogeneous catalyst, e.g. in solution or complexed. Rh is a heterogeneous catalyst, e.g. a solid phase.

Data obtained in the past seven years indicate that the initial $\mathrm{Rh}$ species dissolves and subsequently reprecipitates during the SRAT. ${ }^{9}$ The reprecipitation appears to be on-going about the time that significant catalytic hydrogen generation is initiated. The postulated nitro-rhodium complex catalyst for hydrogen generation may be bound to the surface of the insoluble solids in the sludge, since significant hydrogen generation is seen when the $\mathrm{Rh}$ supernate concentration is a fairly small fraction of the total $\mathrm{Rh}$ in the system $(<10 \%)$. Evidence or experimental data in support of a significant metallic $\mathrm{Rh}$ formation process have not yet been produced.

6) The relative activity is 1) $R u>P d>R h$ (Bond), 2) $P d>R h>R u$ (Müller), or 3) $R h$ $>R u>P d(U . G a$.).

The data from the past seven years supports the University of Georgia sequence, $\mathrm{Rh}>\mathrm{Ru}>$ Pd for catalytic hydrogen generation in the SRAT. ${ }^{9}$

\subsubsection{Features Missing Conclusive Data as of 2002}

The third, and final, list from the 2002 review described some areas that had not been studied and for which there were no data available from which to draw any definitive conclusions. ${ }^{4}$ The discussion below indicates that considerable improvement has been made in understanding most areas where data were missing in 2002. Programs already in progress should further improve the situation. These include the sludge matrix study planned for 2009. The ability of secondary soluble anions to influence the catalytic activity, e.g. by altering the structure of catalytically active complexes based on nitrite, however, is one area that is not covered by any current program. 
1) The presence of oxygen from air purging may reduce the hydrogen generation rate compared to tests with nitrogen or argon purging. This would apparently be due to the catalytic oxidation of formic acid per the March 1991 U. Ga. report. Oxygen depletion is observed during $\mathrm{NO}$ production $\left(\mathrm{NO}+1 / 2 \mathrm{O}_{2} \rightarrow \mathrm{NO}_{2}\right)$, but only because it is an abrupt and obvious effect. It is harder to track subtle oxygen consumption that occurs over a long period of time (small difference of large numbers). The presence of oxygen may also impact metal ion reduction.

The first inconclusive feature seems to be irrelevant to the current DWPF flowsheet. Oxygen is present in the SRAT air purge. Oxygen depletion during nitrite destruction has not been observed to reach $100 \%$. Production of hydrogen into an inert nitrogen purge is a designed safety feature in DWPF for loss of the air purge system, since $\mathrm{H}_{2}-\mathrm{N}_{2}$ gas mixtures are not flammable.

2) The degree of mixing/agitation may affect hydrogen generation rate and total hydrogen produced. It may also affect the dissolved oxygen content of the sludge. Important processes may be occurring whose rates are mass transfer limited (agglomeration of catalyst nanoclusters, transport of formic acid to active sites, poisoning of catalyst sites, etc.).

Mixing may be a subtle factor affecting hydrogen generation, but the variability of hydrogen generation rate magnitudes as functions of time in repeated SRAT trials makes it unlikely that this can be proven (or consequently is particularly relevant). Surface foaminess and bulk slurry air entrainment are two mechanisms that can lead to gas hold-up, however, which can delay the release of generated hydrogen into the SRAT or SME off-gas space. These processes could dampen the impact of rapid changes in hydrogen generation rate on the observed off-gas concentration at the DWPF GC. This is not seen as a concern, since it is the actual, rather than the potential, hydrogen release rate to the off-gas that would present the hazard.

3) The role of $\mathrm{pH}$, and/or solution potential, on hydrogen generation is not clear. The effect of sludge composition on $\mathrm{pH}$ and solution potential during acid addition is not understood. Half cell reaction potentials indicate that the solution potential must reach a certain range of values before noble-metal catalyzed hydrogen generation is favored. The precise potential is somewhat different for each noble metal.

Increasing $\mathrm{pH}$ levels during SRAT reflux have failed to reach a $\mathrm{pH}$ where catalytic hydrogen generation suddenly shuts down. Data obtained with a commercial platinum oxidationreduction probe (ORP) in the SRAT show a significant swing toward a more oxidizing system just prior to the formation of significant hydrogen in four different systems. The relative milli-volt shift between $0 \%$ and $0.1 \%$ hydrogen in the off-gas is sufficiently large $(100-200 \mathrm{mV})$ that precise redox supernate potentials should not be a critical factor. Two sets of ORP data during hydrogen generation have been documented, ${ }^{10,11}$ while two other data sets from SB6 preliminary flowsheet testing are not yet documented. 
4) Fully activating $R h$ and $R u$ in parallel, rather than in series, would seem to be a worst case scenario for hydrogen generation. Some data seem to show two noble metals becoming significantly active close in time, while other data show two noble metals activating at distinctly different times, and still other data seem to show only a single, relatively mild, noble metal activation (although more than one noble metal might be participating).

As discussed in detail in Section 4.0, Rh appears to become most active when some nitrite is left in the system, while $\mathrm{Ru}$ does not activate until this nitrite is destroyed. Having both species at maximum catalytic activity for hydrogen generation simultaneously seems unlikely during sludge processing with significant nitrite ion in the feed.

5) The role of the sludge particles and their surface potentials on noble metal catalysis is not understood. Would changing the sludge particle characteristics effect the morphology (and simultaneously the activity) of reduced noble metal solids formed during reduction?

The impact of the composition of the surrounding media on the catalytic activity of the noble metals has not been studied systematically. The planned sludge matrix study testing, including the proposed supplemental hydrogen generation program tests, should provide an indication of the possible significance of these factors. Testing with sheared and unsheared SB5 simulants did not show a significant impact on hydrogen generation from an increase in total insoluble particle surface area at constant composition. ${ }^{19}$

6) The presence of other anions, e.g. sulfate, chloride, etc., appears to bear on the precise hydrogen generation rate achieved. The magnitude of the effects of these anions at various washed waste levels on hydrogen generation is not understood. A few model system data points suggest that these may be second-order effects not critical to a first-order understanding of hydrogen generation.

The effect of variations in the concentrations of the stable soluble anions, such as sulfate, chloride, etc., on catalytic hydrogen generation has not yet been studied systematically. It would not be unreasonable to expect some effect if noble metal ligand-driven catalysis (catalysis by complexes based on noble metal cations with system anions) is the predominant mechanism.

7) The role of silver in promoting the formation of impure noble metal alloys is not understood, but it appears that the alloys are less active than the pure noble metals.

The point arose from literature studies, not site studies. Silver alloys are unlikely to be formed during SRAT processing, since the precipitated silver species in the starting sludge appears to be essentially inert and stable during processing. ${ }^{9}$ Therefore silver metal is not formed, and consequently metallic silver alloys should not be present. 


\subsection{STATUS OF 2005 HYDROGEN REVIEW ISSUES}

The 2005 review of catalytic hydrogen generation brought in the SB3 simulant test data which covered a broad range of wash endpoints and oxalate concentrations. The primary

new findings related to the role of the oxalate ion, some of which converted to formate ion, ${ }^{27}$ and some of which tended to either consume or tie up some of the acid protons added as nitric and formic acid. Considerable effort was expended in trying to generalize the current DWPF stoichiometric acid equation to account for the effect of oxalate. The revised equation that was proposed, however, was based almost entirely on SB3 simulant test data. The impact of oxalate on acid consumption in the SB3 compositional matrix may not generalize to other sludge batch compositions.

Sludge Batch 3 testing was ultimately redirected to much lower oxalate ion concentrations $(<4,000 \mathrm{mg} / \mathrm{kg})$. Subsequent SB3 SRAT simulation data showed that regions exist in the acid stoichiometry window where the maximum hydrogen generation rate did not change significantly with changing stoichiometric factor, but where the timing of the peak

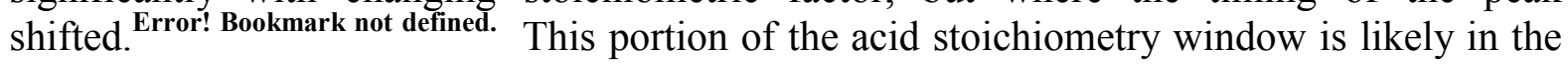
region where interactions between the various factors contributing to hydrogen generation are most significant. More information was obtained about this phenomenon in the 20072008 Rh-Ru-Hg matrix study. ${ }^{13}$

Some preliminary work on the effect of heels has been undertaken. ${ }^{28}$ Most of the SB4 testing with heels did not produce significant hydrogen, so the data did not lead to confirmation of past observations or to any new findings. An earlier SB3 flowsheet blend test pair showed an impact on hydrogen generation; however the acid addition calculations were not performed in a prototypical manner for the two systems (acid for the test with a heel was not based on a SRAT receipt sample analysis). ${ }^{28}$

\subsection{5-2006 SIMULANT FINDINGS}

All simulant studies covered by the two internal reviews ${ }^{4,5}$ used trimmed noble metals. Progress on understanding the mechanisms of catalytic hydrogen generation continued during the period leading up to the SB4 qualification SRAT/SME cycle in the Shielded Cells in 2006. This period included the coprecipitated noble metal comparison tests versus trimmed noble metals. ${ }^{6,7}$ These tests indicated that coprecipitated noble metals apparently took longer to activate fully for hydrogen generation than trimmed noble metals. The tests did not indicate the mechanism for the delay, e.g. the tests did not establish whether or not the delay in activation was due to slower nitrite ion destruction (see Section 4.0 for a discussion of how nitrite ion affects $\mathrm{Rh}$ and $\mathrm{Ru}$ catalysis) or were due to an inhibited release sequence of the noble metals from the insoluble sludge solids matrix.

During the form of noble metal testing, a series of trimmed noble metal runs was performed at four different noble metal loadings. The four tests showed that the maximum hydrogen generation rate occurred later in the SRAT cycle as the noble metal concentration decreased at constant acid stoichiometry. Therefore, one interpretation of the coprecipitated noble 
metal peak hydrogen generation rate delay was that it was due to a smaller fraction of the available noble metals participating in the reactions leading up to the peak.

The cumulative simulant SRAT data sets through SB4 qualification also suggested the presence of a middle ground region where hydrogen generation behavior is more complicated, or less predictable, than under bounding conditions. Bounding conditions could be defined as very large or small concentrations of noble metals coupled with very large or small amounts of excess acid. Hydrogen generation generally has increased with increasing noble metal concentration and/or increasing quantity of excess acid in the bounding condition combinations.

In the SB3 acid window flowsheet study, middle ground was identified when the $155 \%$ case matched the $170 \%$ case for peak concentration, but at a later time. ${ }^{\text {Error! Bookmark not defined. In }}$ the source of alkali testing, middle ground was seen when the lower acid $8 \%$ Na case peaked faster and higher than the higher acid 4\% Na case. In SB3 flowsheet studies, there were instances where delayed hydrogen peaks were seen that led to issues with SME hydrogen generation. The common theme was that peak hydrogen generation typically corresponded to concentrations in the $0.1-1.0$ volume $\%$ range.

Increasing acid beyond this middle ground generally gave a sharp, early hydrogen generation peak that was higher than any subsequent peak. Decreasing acid below the middle ground generally gave a low, sustained concentration of hydrogen with subdued to nonexistent peaks in generation rate. Tests at $65 \%$ and $100 \%$ of the nominal trimmed noble metal concentration in the experimental work associated with the investigation into the impact of the form of noble metals showed what might be defined as behavior not typically seen when using extreme conditions. This pair of runs showed increased hydrogen generation rates with lower noble metal concentrations.

Previous hydrogen generation findings were generally not contradicted by the 2005-2006 data. The new data did expand the understanding of what different types of hydrogen generation rate data might be possible. Previous findings from the catalytic hydrogen generation program related to mercury-noble metal interactions were not contradicted by the SB3-SB4 data. Collectively, the 2005-2006 data improved the characterization of the region of reduced sludge washing (high nitrite SRAT feed) coupled with higher noble metal concentrations compared to sludge batches $1 \mathrm{~A}$ and $1 \mathrm{~B}$.

Data from the initial actinide removal process (ARP) flowsheet testing supported the hypothesis that the current DWPF stoichiometric acid equation had potential issues in dealing with variable feed compositions due to the impacts of varying amounts of salt processing streams on the SRAT receipt sample composition. SRAT simulation data were used in developing a methodology for off-setting changes in supernate acid consumers by adjusting the stoichiometric factor. This methodology could be extended to other waste streams brought into existing sludge batches during CPC operations.

The adjusted stoichiometric factor methodology could have been applied to the added caustic test of SB3, and it would have led to lower acid addition and less hydrogen generation. The 
adjusted stoichiometric factor methodology could have been adapted to the source of alkali study to give a range of stoichiometric factors that left about the same quantity of excess acid in each of the five different SRAT tests. Instead, a single stoichiometric factor was used which gave behavior ranging from marginal nitrite destruction in the low sodium feed cases to significant hydrogen generation in the high sodium feed cases. The obvious alternative to the adjusted stoichiometric factor methodology, however, was the development of a more accurate stoichiometric acid equation for the SRAT.

Limited data on the impact of a heel, or of SRAT product, on hydrogen generation were obtained since 2003. These data suggested some degree of inhibition on hydrogen generation, but the details are not clear. The 22-L data indicated that it was not merely a question of dilution of key species leading to lower reaction rates because of lower concentrations, since the dilutions were minor. A potential poisoning effect on the noble metals could be occurring. The 4-L data with a prototypically sized heel, however, still showed a significant hydrogen generation rate. This implied that there is a limit to what a heel could do to inhibit hydrogen generation.

The one common result of heel-related testing was that omitting a heel has so far led to conservatively high hydrogen generation rates. Comparing runs with a prototypical heel to runs with a smaller heel is complicated for the same reasons that the comparisons in the form of noble metal test program were difficult. It is difficult to adjust the acid addition to give nearly identical quantities of excess acid when the inputs to the stoichiometric acid calculation change (the sludge that was used for trimmed noble metal comparisons was not $100 \%$ identical to the sludge containing the coprecipitated noble metals). Heel studies are further complicated by issues such as whether or not to consider manganese from the heel as already processed, or in need of further processing, and whether or not to consider noble metals in the heel as partially deactivated or potentially still fully active.

\subsection{RECOMMENDATIONS MADE BY THE TECHNICAL REVIEW PANEL}

An independent technical review panel was convened in December 2006 to evaluate the current understanding of catalytic hydrogen generation following the unexpected high concentrations in Sludge Batch 4 qualification work (SC-0), as well as the SRNL research program that was investigating catalytic hydrogen generation in DWPF. The panel issued a summary report in March 2007 that included five short-term, six mid-term, and two longterm recommendations for follow-up activities. Error! Bookmark not defined. Table 5 summarizes the status of progress on these recommendations at a high level. A more extensive discussion of progress on each recommendation follows in Sections 3.4.1 to 3.4.3. 
Table 5. Status of Expert Panel Recommendations

\begin{tabular}{|l|c|c|c|}
\hline Abbreviated recommendation description & $\begin{array}{c}\text { Recommended } \\
\text { timing }\end{array}$ & $\begin{array}{c}\text { Nearly } \\
\text { complete }\end{array}$ & $\begin{array}{c}\text { Significant } \\
\text { work still } \\
\text { needed }\end{array}$ \\
\hline Rerun SC-0 qualification SRAT/SME & Short-term & $\mathrm{X}$ & \\
\hline Replicate SC-0 events using simulant & Short-term & $\mathrm{X}$ & \\
\hline Perform statistical study on $\mathrm{H}_{2}$ generation & Short-term & $\mathrm{X}$ & \\
\hline Re-analyze existing $\mathrm{H}_{2}$ data & Short-term & $\mathrm{X}$ & \\
\hline Develop better predictions for noble metals & Short-term & $\mathrm{X}$ \\
\hline Determine SRAT reaction sequence & Intermediate & $\mathrm{X}$ & \\
\hline Develop more robust formic acid strategy & Intermediate & $\mathrm{X}$ & \\
\hline Find minimum Hg concentration to block $\mathrm{H}_{2}$ & Intermediate & $\mathrm{X}$ & \\
\hline Study MCU/ARP impacts on $\mathrm{H}_{2}$ & Intermediate & $\mathrm{X}$ & \\
\hline Reduce formic acid use in DWPF & Intermediate & & $\mathrm{X}$ \\
\hline Rationalize historic $\mathrm{H}_{2}$ data & Intermediate & $\mathrm{X}$ & $\mathrm{X}$ \\
\hline Find rapid screening techniques for $\mathrm{H}_{2}$ & Long-term & & $\mathrm{X}$ \\
\hline Develop smaller scale methodologies & Long-term & & \\
\hline
\end{tabular}

A detailed breakdown of progress with respect to each of these recommendations is given in the three sub-sections that follow (by time window).

\subsubsection{Near-term Recommendations}

This section provides additional detail on progress made on the five short-term recommendations (6-12 month completion target) made by the expert panel:

1. Rerun the Sludge Batch 4 qualification run in SRNL's Shielded Cells with actual waste, in the same manner as before, without overheating the material.

2. Reproduce the Sludge Batch 4 qualification run using simulated waste, including overheating of the material.

3. Carry out a statistically-designed study to identify the major contributors to hydrogen generation and to provide a basis for an improved prediction of the amount of formic acid that should be added during SRAT processing.

4. Re-analyze existing data to gain a more quantitative understanding of hydrogen generation. The same approach should be applied to future experiments.

5. Develop more accurate projections for sludge compositions and noble metals concentrations likely to be encountered.

Items \#1 and \#2 were completed in FY07. ${ }^{29}$ Analytical results of the fresh SB4 sample used for the repeated SRAT/SME test (SC-3) varied more than expected from those of the original qualification sample. A comparable acid addition, as moles acid/L sludge slurry, was made that led to lower levels of hydrogen generation than in SC-0. Follow-up simulant tests focused on various features of SC-0 (such as the altered processing timeline, form of the mercury, etc.) also failed to reach the hydrogen generation levels seen in SC-0. Nevertheless, all of these simulations produced from $10-35 \%$ of the DWPF limit for hydrogen in the SRAT confirming that significant catalytic activity was present. Follow-up SME cycles reached 
half of the DWPF hydrogen generation rate limit. One phenomenon observed was that some of the simulant SME slurries thickened considerably during final dewatering, which may have led to hot wall effects, and which, regardless of mechanism, had an associated period of enhanced hydrogen generation just prior to ending the test.

Two other phenomena were noted at the time of the initial SC-0 SME cycle hydrogen excursion: the ratio of $\mathrm{N}_{2} / \mathrm{O}_{2}$ increased from about four to 6.5 (typical of $\mathrm{O}_{2}$ loss to $\mathrm{NO}$ to form $\mathrm{NO}_{2}$ ) and there was significant $\mathrm{N}_{2} \mathrm{O}$ generation. Both are symptoms normally associated with nitrite destruction in the SRAT cycle that suggest there may have been mixing and sampling issues with the SC-0 SRAT cycle (no nitrite in SRAT product, but nitrite was seen in the SME product analysis) that resulted in some fraction of the slurry being isolated and non-reactive during the SRAT causing these reactions to be delayed until the SME cycle.

With respect to the third item: the major contributors to hydrogen generation have been identified as $\mathrm{Rh}, \mathrm{Ru}$, and excess acid as elaborated on in the current understanding of hydrogen generation in Section 4.0. Significant progress has been made on improving the prediction of the amount of formic acid required during SRAT processing, Section 4.3. Two new stoichiometric acid equations are undergoing validation tests. A statistically-designed sludge matrix study is in progress that could identify any factors that might be impacting hydrogen generation that may have been over-looked in the work to date.

Existing and new data have demonstrated that accurate quantitative prediction of hydrogen generation rates will be difficult, item \#4. Section 3.5 contains further details, but the issues revolve around the fairly complex chemistry near the end of nitrite destruction, and the ways in which formic acid, $\mathrm{Rh}, \mathrm{Ru}, \mathrm{Pd}$, and $\mathrm{Hg}$ alter nitrite destruction kinetics and consequently impact catalyst activation, deactivation, and hydrogen generation.

Progress on the fifth item goes beyond the direct control of SRNL, which does not determine the make-up of future sludge batches or control tank sampling. SRNL depends on Liquid Waste Operations for early sampling and characterization of the waste tanks selected for upcoming sludge batches. The continued importance of these samples cannot be understated from the perspective of simulating catalytic hydrogen generation in DWPF. It should be noted that projections of future sludge batch compositions are often unreliable, since changes to the final sludge batching strategy often arise during the preparation process. For example, issues with sludge removal from a tank can delay processing of that material from the planned sludge batch. These changes not only impact the sludge batch being prepared, but subsequent batches as well.

\subsubsection{Intermediate-term Recommendations}

This section provides additional detail on progress made on the six intermediate-term recommendations (1-2 years completion target) made by the expert panel:

1. Determine the sequence of reactions, particularly the onset of hydrogen generation, and identify the process variables that signal the onset of hydrogen generation.

2. Develop a more robust approach to formic acid addition. 
3. Determine whether there is a minimum SRAT mercury concentration that can prevent excessive hydrogen generation.

4. Determine the impacts of salt decontamination products coming from the MCU/ARP and the Salt Waste Processing Facility on hydrogen generation.

5. Reduce the amount of formic acid going into the SRAT and SME.

6. Understand and rationalize all of the historic hydrogen generation data.

Significant progress was made on item \#1 in 2008. Data were obtained that permitted the construction of a SRAT reaction timeline covering acid addition and the period shortly thereafter which overlapped the onset of hydrogen generation. Noble metal and nitrite ion behavior during the period of the onset of hydrogen generation were obtained and correlated as summarized in Sections 4.1 and 4.2. The final stages of nitrite ion destruction were found to coincide with the onset of hydrogen generation, but laboratory attempts to develop real time monitoring of nitrite ion concentration in the SRAT supernate, for example by laser Raman spectroscopy, have not been equally successful.

Significant hydrogen generation appears to be accompanied by a fairly large decrease in the ORP potential (shift toward a less reducing/more oxidizing supernate concentration), but the millivolt change can occur over just a few minutes when the maximum hydrogen generation rate is ultimately at or above the DWPF SRAT design basis. Consequently, the usefulness of ORP readings as a predictive/preventive tool appears limited, but more data will be obtained to better understand and confirm this.

DWPF has recently made the secondary SRAT GC column operational that reports $\mathrm{CO}_{2}$ and $\mathrm{N}_{2} \mathrm{O}$. This creates opportunities for correlating these gas generation rate profiles in the plant with the timing of the end of acid addition and the onset of hydrogen generation that did not exist in 2007-2008. For example, it may be that shutting off further acid additions once the $\mathrm{N}_{2} \mathrm{O}$ concentration has fallen to some fraction of its maximum value could be considered as a potential strategy to avoid over-adding acid.

Lab-scale data indicate that $\mathrm{N}_{2} \mathrm{O}$ generation occurs during nitrite destruction, and that the majority of nitrite destruction occurs prior to hydrogen generation. As the $\mathrm{N}_{2} \mathrm{O}$ concentration starts to fall during runs at the equivalent of two gallons per minute formic acid, typically over half of the initial nitrite has been destroyed. Presumably the amount of additional acid that should be added to complete nitrite destruction can not be a very large fraction of the planned total addition once this point is reached. Actual lab-scale tests of the feasibility of this strategy and the supporting calculations that would suggest when the acid should be shut off relative to the $\mathrm{N}_{2} \mathrm{O}$ profile have not been authorized. This is a potential area for further study.

Data from the same SRAT simulation experiments described above, combined with historical data, were used to construct two new approaches for predicting the quantity of acid required to process a SRAT batch, item \#2. ${ }^{10,17}$ A second generation equation, derived from the existing DWPF stoichiometric acid equation (Hsu-Marek-Eibling, or first generation equation), was developed that is typically within $\sim 10 \%$ of the required acid for nitrite destruction. The new equation is, on average, predicting somewhat more acid than 
absolutely necessary for nitrite destruction, potentially due to over-stated expected Mn reduction. Work continues on refining this equation with the goal of implementing it in DWPF. The second equation, based on soluble cations, provides an independent check on equations that draw much of their predicted demand from titrated base equivalents, carbonate ion, and nitrite ion acid requirements. The cation equation appears to be susceptible to variability in the sodium ion measurement, which is a quantity of comparable magnitude to the predicted acid demand.

The issue of mercury, item \#3, was investigated in detail during 2007-2009. It does not appear to be feasible to control the hydrogen generation reactions by exploiting mercury as a poison. Testing at several non-zero levels of $\mathrm{Hg}$ typical of plant wastes showed negligible benefits from increasing the initial concentration by a factor of five. The primary benefit appears to come from having some small amount of $\mathrm{Hg}$ in the starting sludge $(0.1-0.5 \mathrm{wt} \%$ in total solids) versus none at all. Above $0.5 \mathrm{wt} \% \mathrm{Hg}$ in the total solids, there was very little if any benefit from mercury, whereas there are other processing issues associated with larger quantities of $\mathrm{Hg}$ in the Chemical Process Cell and/or in the melter off-gas system.

Data suggest that one of the roles of $\mathrm{Hg}$ was as a promoter of nitrite destruction, which effectively altered the activation and deactivation rates of the proposed nitro-rhodium complex responsible for some of the most extreme hydrogen generation rates. Presently, this doesn't appear to be directly linked to the effect achieved by having some mercury versus having no mercury. Consequently, there appear to be at least two distinctly different mechanisms by which mercury is impacting catalytic hydrogen generation.

Additional simulant testing related to item \#4 (salt processing impacts) has taken place. The impacts of the ARP and MCU streams have been relatively benign, as long as the impacts on the stoichiometric acid calculation have been accounted for properly. The second generation stoichiometric acid equation should help in this regard by better predicting the true acid requirement and reducing the dependence on empirical correction factors. Testing with MST, with and without radioactive activation, showed negligible impact on catalytic hydrogen generation.

Item \#5, reduce the amount of formic acid going to the SRAT and SME, has been examined from several perspectives. The formic acid in the frit slurry can apparently be eliminated from the SME whenever the need justifies the effort. The improved stoichiometric acid equations should facilitate reducing formic acid going to the SRAT by better controlling total acid in general. ${ }^{10,17}$ Beyond these two obvious approaches, SRNL was asked to investigate revisions to the DWPF process flowsheet that would either eliminate formic acid completely or reduce usage significantly. No single organic acid was found that could act as a suitable replacement with respect to reducing $\mathrm{Hg}$ for steam stripping in the $\mathrm{CPC}$. It was found, however, that solutions of formic acid with glycolic acid (perhaps 20:80 formic to glycolic acid by moles or less) had the potential to be effective at reducing $\mathrm{Hg}$. Such solutions replace much of the reducing capability of formic acid under melter conditions with glycolic acid (preliminary documentation of this work is in progress, but a direct reference is not yet available). 
The effort to rationalize all of the historical data on catalytic hydrogen generation at SRS, item \#6, constitutes Sections 3.1 to 3.3 of this report, plus the synthesis of what has been learned in the form of a summary in Section 4.0. Sections 3.1 to 3.2 reexamined the issues raised during two internal reviews of catalytic hydrogen generation work at SRS and at offsite laboratories, while Section 3.3 covered progress made between the second internal review and the convening of the external review panel. The discussion in Section 4.0 brings the review of existing data on catalytic hydrogen generation in the DWPF SRAT and SME cycles up to the present day and summarizes the current understanding of the chemistry.

\subsubsection{Long-term Recommendations}

This section provides additional detail on progress made on the two long-term recommendations (expected duration $2+$ years) made by the expert panel:

1. Develop screening approaches that can more rapidly and easily identify the potential for excessive hydrogen generation in the DWPF prior to waste qualification.

2. Develop smaller-scale simulant testing methodology, and use it to resolve key issues relating to hydrogen generation, noble metal behavior, and SRAT/SME chemistry.

The new stoichiometric acid equations constitute one of many possible screening approaches that can be used to identify the potential for excessive hydrogen generation, item \#1. Formic acid additions above the prediction of this equation are expected to have an increasing potential for excessive hydrogen generation depending on how much additional acid is added. At present, this information cannot be combined with information about sludge composition (nitrite, $\mathrm{Rh}, \mathrm{Ru}, \mathrm{Hg}$ ) to predict the hydrogen generation rates of a given SRAT experiment.

One issue that interferes with creating a general model of hydrogen generation is the apparent variability of repeated trials. The bead-frit and $\mathrm{Rh}-\mathrm{Ru}-\mathrm{Hg}$ matrix study runs were susceptible to much greater variability in hydrogen generation rates than in $\mathrm{CO}_{2}$ generation rates. These tests were near or above the DWPF limit for hydrogen generation in the SRAT, so they are not typical of where DWPF normally operates. Variability of $50 \%$ was found within individual run pairs for the hydrogen generation rates and profiles, although variability in $\mathrm{CO}_{2}$ generation was of order $5 \%$ or less in repeated trials during periods of significant $\mathrm{CO}_{2}$ generation $(>1-2 \%)$. An intermediate level of variability was seen in $\mathrm{N}_{2} \mathrm{O}$ generation. In many of these tests, the peak hydrogen generation rate occurred between the end of formic acid addition and the end of dewatering.

Over $95 \%$ of a $\sim 20$ hour long lab-scale SRAT simulation is held to a very tight operating protocol. The period immediately following formic acid addition leading into boiling, however, can be one of the variable periods. This 25-45 minute period was closely associated with significant hydrogen generation due to Rh catalysis as well as the effective end of nitrite destruction in many of the recent hydrogen program tests. Temperature versus time profiles varied during these periods in what were otherwise matched pairs of runs. Having temperature-time profile variations meant there were variations in kinetic rate constants versus time as well. These reaction rate variations may have coincided with what was a critical period for maximizing hydrogen generation, and they may have contributed to 
some of the variability that was seen in the hydrogen data. More traditional SRAT simulations generally have the peak hydrogen generation rate come much later after the SRAT has been boiling steadily for one or more hours, and SRAT replicates may not show as large a variability in peak hydrogen generation rates.

With respect to item \#2, development work has been underway since early 2008 on smallerscale testing methodologies. Various practical processing issues have been encountered. These include moving low volumes of gas through small diameter tubes such that the residence times stay under a few minutes as well as mixing some of the sludge simulants. The simulants are sufficiently viscous that traditional magnetic stirring bars either become uncoupled or give poor mixing.

In summary, the intent of the eleven specific near-term and mid-term issues was substantially met over subsequent the two-year period. Progress is on-going on the two longer term recommendations.

\subsection{GENERAL STATUS OF CATALYTIC HYDROGEN GENERATION PROGRAM}

The interplay of either $\mathrm{Rh}$ or $\mathrm{Ru}$ with nitrite ion, acid, and mercury in the context of sludge processing in the SRAT appears to involve fairly complex chemistry. Having both noble metals present in a fission yield ratio of about $3.75 \mathrm{Ru}$ per $\mathrm{Rh}$, and with $\mathrm{Rh}$ apparently a superior catalyst to $\mathrm{Ru}$ initially, means that both noble metals are likely to participate in hydrogen generation rather than one. Catalytic hydrogen generation cannot be simplified to the study of just one noble metal. Both the $\mathrm{Rh}$ and $\mathrm{Ru}$ reaction sequences must be considered simultaneously, which further complicates data analysis, development of general trends, construction of kinetic models, etc.

About half of the simulations in the recent $\mathrm{Rh}-\mathrm{Ru}-\mathrm{Hg}$ matrix study had an event that occurred sometime during the twelve hour reflux period (generally in the second half) where there was a sudden significant increase in hydrogen generation rate. For certain $\mathrm{Rh}-\mathrm{Ru}$ combinations, the resulting hydrogen generation rates exceeded those seen earlier in the SRAT cycle. In addition, two out of the three midpoint runs (identical $\mathrm{Hg}$, noble metals, and acid stoichiometry) had maximum hydrogen generation rates in the first two hours after formic acid addition while the maximum hydrogen generation rate in the third trial was about an hour before the end of reflux, or about ten hours later.

The experimental work from the past few years has shown that there are some statistically significant non-linear effects in the normal range of likely noble metal and mercury concentrations. The potential exists that certain generalizations could emerge from subsets of data that are only valid for limited ranges of possible behavior because of the non-linear structure of hydrogen generation as a function of the factors. For example, generalizing that increasing $\mathrm{Hg}$ always leads to a decrease in the maximum hydrogen generation rate appears to be invalid above a critical $\mathrm{Hg}$ concentration. Attempting to use an improper generalization during a paper study covering a new region of processing behavior could potentially lead to a prediction that is the opposite of what would actually occur. 
A short list of some $\mathrm{Rh}-\mathrm{Ru}-\mathrm{Hg}$ chemical issues that remain particularly speculative or completely unknown is given below:

- The nature, oxidation state, and potential catalytic activity of the $\mathrm{Rh}$ species associated with the insoluble solid that forms near the end of acid addition. (Is it nearly inert or still quite active?)

- The extent that $\mathrm{Rh}$ is reduced to the element. (Does $\mathrm{Rh}^{0}$ actually form in the SRAT, and to what extent? XAS studies on the Rh samples have not been performed yet, but are planned for the coming year.)

- The active form of supernate $\mathrm{Ru}^{3+}$ for hydrogen generation. (Is it a complex? Could it be a complex with formate ion?)

- The nature, oxidation state, and potential catalytic activity of the Ru precipitate that forms late in CPC processing (after the Ru peak rate). (Is there a truly significant insoluble catalyst phase during the SME cycle?)

- The chemistry of any Hg-noble metal interactions, e.g. is it primarily indirect through altered nitrite destruction kinetics, or is there a more direct impact through amalgams, open noble metal solid structures, etc. (Outside assistance is needed to draw conclusions about $\mathrm{Hg}-\mathrm{Rh}$ and $\mathrm{Hg}-\mathrm{Ru}$ chemical interactions from XAS data.)

- The extent that redox control impacts hydrogen has been studied previously, but never systematically over a broad range of sludge compositions and acid demands. It is possible to envision situations where increasing the formic acid fraction of the total acid could actually lead to a small reduction in maximum hydrogen generation rate instead of the expected increase.

The current strategy for controlling hydrogen generation can be summarized as find a region of acid addition that limits the excess acid and thereby limits the maximum hydrogen generation rate. This strategy is fundamentally sound. The basis for implementing this strategy appears to be even stronger today than it was four years ago. The following potential shortcomings with the current strategy are listed below without regard to their possible severity:

- The acid addition region must be defined empirically for each sludge batch using simulant experiments and validated with one or more lab-scale tests using real waste.

- The method of adjusting the acid addition for changes in composition currently uses an equation that contains some potential omissions, double-counting, and other issues. These issues limit usefulness of the equation as a predictive tool to small ranges in the inputs centered on the experimentally determined test window conditions.

- Future sludge batch compositions could be proposed that would have an unacceptably small region of acid addition. It might be impractical to claim that every run would stay within the acceptable region due to process and analytical measurement uncertainties, etc. The current strategy would reject the proposed sludge composition as unsuitable, where an alternative strategy might be able to process it.

The second generation stoichiometric acid equation (revised, expanded Hsu/Marek/EiblingDWPF equation) could help significantly with burger dots one and two. It appears to be 
predicting acid demand fairly closely without any significant empirical adjustment during initial evaluations, and it appears to have alleviated the issues of significant omissions and double-counting in the current DWPF stoichiometric acid equation. Various alternative strategies are possible for controlling hydrogen generation. These alternative strategies are likely to have their own lists of shortcomings which are not fully enumerated here. Some potential strategies include:

- Process the SRAT/SME such that nitrite never falls below $1000 \mathrm{mg} / \mathrm{kg}$. This should inhibit both $\mathrm{Rh}$ and $\mathrm{Ru}$ and eliminate catalytic hydrogen. (A variation of this would be to add sodium nitrite to the SRAT to maintain a non-trivial nitrite ion concentration. A successful initial demonstration SRAT simulation has been performed. ${ }^{16}$ )

- Fabricate functionalized mesoporous silica particles that can be added with the SRAT receipt slurry to chemically trap the $\mathrm{Rh}$ and $\mathrm{Ru}$ atoms onto the particles and eliminate the catalysts (simple scoping tests have shown positive results). ${ }^{30}$

- Modify the DWPF flowsheet so a change in redox control strategy is possible, i.e. take formic acid out of the role as the sole reductant (have a multiple reductant strategy).

- Replace formic acid completely with one or more alternative reductants and use nitric acid as the only acid.

- Develop logic driven by $\mathrm{CO}_{2}$ or $\mathrm{N}_{2} \mathrm{O}$ GC data that would shut down acid addition if the Mn-nitrite reduction reactions appeared to have progressed sufficiently far before the planned end of acid addition.

Current work at SRNL is focused on improving the understanding of acid consumption and reducing uncertainties in the stoichiometric acid addition equation. This should produce a superior tool for use in the current hydrogen control strategy (refined second generation stoichiometric acid equation). A preliminary evaluation of alternative flowsheets has been promising, and more work on reducing the role of formic acid and/or sequestering the noble metals has been recommended. 


\subsection{CURRENT UNDERSTANDING OF HYDROGEN GENERATION}

The various findings from a series of programs to investigate SRAT chemistry and catalytic hydrogen generation have begun to form a coherent whole. This section presents the best current explanation of how various factors interact to produce hydrogen catalytically in the DWPF CPC. Six primary factors have been identified as significant to SRAT catalytic hydrogen generation. These include:

- Concentration of Rh (Section 4.1)

- Concentration of Ru (Section 4.2)

- Initial concentration of $\mathrm{Hg}$

- Acid beyond the requirements for nitrite destruction and Mn reduction (Section 4.3)

- Fraction of acid that is formic acid (no formic acid - no hydrogen)

- Timing and rate of nitrite destruction

Mercury and nitrite destruction are covered in the discussions of noble metal catalysis in both Sections 4.1 and 4.2. With regard to the fraction of total acid that is formic acid, it has so far been found that less formic acid leads to less hydrogen production for a fixed amount of total acid.

\subsection{CPC CATALYSIS BY RHODIUM}

Rh appears to have a period of heightened catalytic activity near the end of nitrite ion destruction. Hydrogen can be produced in excess of the DWPF SRAT limit during this period based on numerous prior experiments. This is also the period where it may be possible to have stable nitro-Rh complexes that can convert formic acid to hydrogen. At high nitrite ion concentrations (relative to $\mathrm{Rh}$ ), the complexes are apparently saturated with nitro group ligands and unable to process formic acid by ligand exchange reactions, while the eventual destruction of nitrite ions in the SRAT effectively eliminates nitro-Rh complexes and brings this form of catalysis to an end. The duration of the final stages of nitrite destruction is a function of the acid stoichiometry and other species in the sludge, including $\mathrm{Hg}$ and $\mathrm{Pd}$.

One unusual occurrence in the period of heightened $\mathrm{Rh}$ activity is that conditions that accelerate nitrite destruction can potentially shorten the period of hydrogen generation. The hydrogen generation rate becomes a sharper and sharper peak when plotted versus time. Increasing the $\mathrm{Rh}$ concentration can accelerate nitrite destruction, shortening the period of maximum activity, and potentially reducing the maximum hydrogen generation rate observed in this period. The effects of $\mathrm{Pd}$ and $\mathrm{Hg}$ also appear to be able to accelerate nitrite destruction relative to $\mathrm{Rh}$ alone, causing the period of heightened activity to shorten, and the maximum generation rate attributable to a nitro-Rh complex to fall. This behavior has been observed when hydrogen generation initiates during formic acid addition.

The presumptive mechanism for getting less hydrogen from more $\mathrm{Rh}$ is a reduction in the concentration of the active nitro-Rh species at the time when excess acid is available for 
conversion into hydrogen. Increasing $\mathrm{Rh}$ causes the available nitro groups to be spread to more $\mathrm{Rh}$ atoms, so the active nitro-Rh complex must appear sooner, when more nitrite is available. This is often during acid addition, when the maximum amount of excess acid is not yet available. Increasing $\mathrm{Pd}$ and $\mathrm{Hg}$ also appears to deplete the nitrite ion supply more quickly causing $\mathrm{Rh}$ to activate sooner when it may be less effective at producing hydrogen under certain acid addition strategies.

When a conservative acid addition strategy is employed, nitrite ion undergoes a very gradual destruction in the SRAT. Graphs of nitrite ion destruction have been prepared for many previous sludge batches at the low end of the stoichiometric factor window. The decline in nitrite ion concentration is nearly first-order in nitrite ion concentration. Graphs of the logarithm of nitrite ion concentration versus time for the period after acid addition have been nearly linear. Preparation of these graphs was more common during the earlier sludge batches when nitrite concentration data was obtained every few hours during boiling in the SRAT cycle. For example, the simulant report on the alternative Tank 51 sludge-only process demonstration (SB1A) included graphs of this type in Appendix A-1 for the thirteen Phase 2 runs. ${ }^{31}$ Nitrite ion concentration data taken during SB1B simulant tests in the $1 / 240^{\text {th }}$ scale SRAT are plotted versus time in Figure 1.

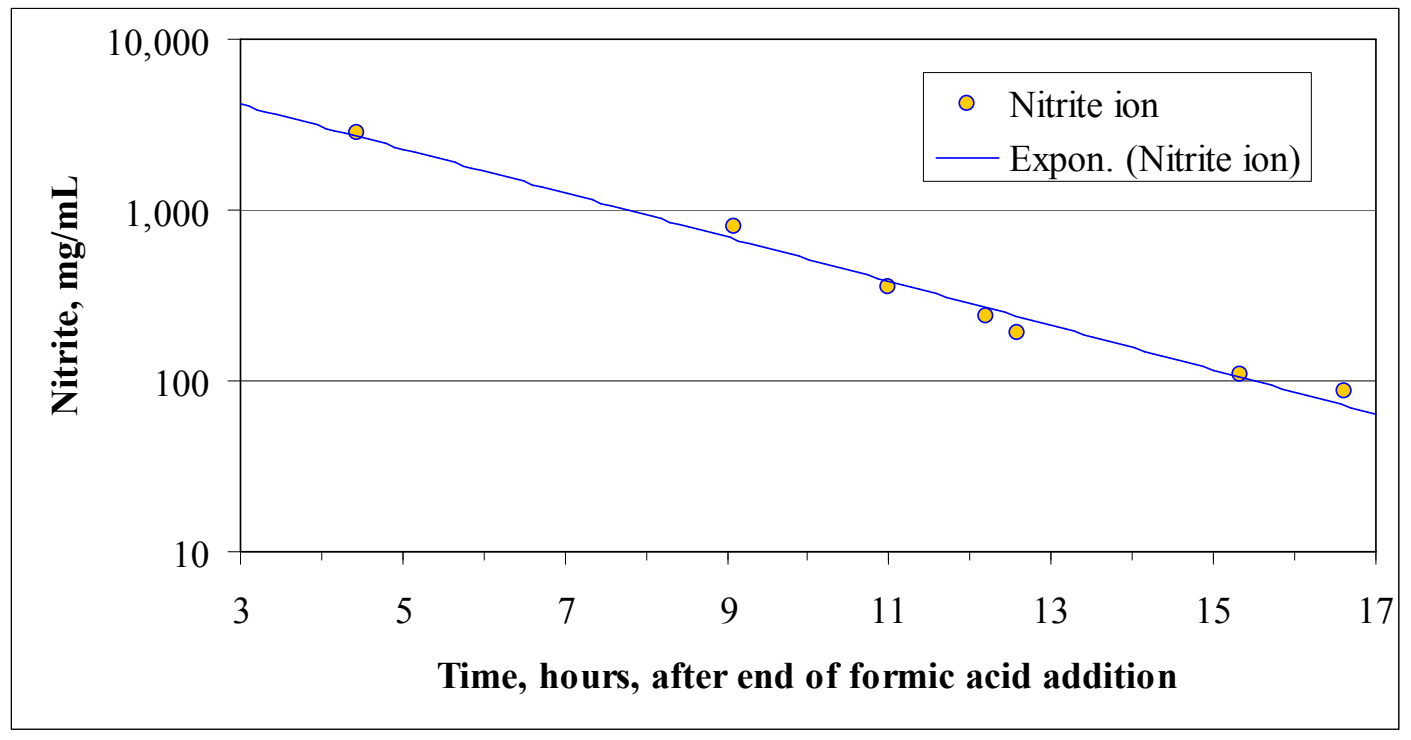

Figure 1. Example of nitrite ion destruction data

The graph is typical of the historical data on nitrite destruction during reflux. Formate concentration was relatively constant during this test. The semi-log format is the correct one for plotting data for a reaction following first-order reaction kinetics. The regression had an $\mathrm{R}^{2}>0.98$. Nevertheless, nitrite ion destruction is not a true first-order reaction. The firstorder rate constants obtained from different cases vary significantly. This is expected, since nitrite ion is relatively stable in the waste supernate until the $\mathrm{pH}$ falls to about 5.5. This indicates that at least one other species, for example formic acid concentration, impacts the reaction rate. Therefore, nitrite destruction follows pseudo-first-order kinetics: 


$$
-\frac{\mathrm{d}\left[\mathrm{NO}_{2}^{-}\right]}{\mathrm{dt}}=\text { rate constant } *\left[\mathrm{NO}_{2}^{-}\right] *(\text { relatively constant term }(\mathrm{s}))
$$

The unknown "relatively constant terms" are needed to explain variations in the observed first-order rate constant between different tests with different acid stoichiometries, noble metal loadings, etc. They are assumed to be relatively constant in a given run, but to vary by non-trivial amounts between runs.

In systems with significant nitrite ion concentration $(>100 \mathrm{mg} / \mathrm{kg}$ ) during boiling, $\mathrm{Rh}$ is not expected to enter the period of heightened activity until late in the SRAT or during the SME cycle (assuming nitrite is eventually destroyed). The period of activity could be considerably longer than in a high acid run due to the slow rate of nitrite destruction, but the off-setting effect is that the minimal quantity of excess acid that is available leads to a small to modest hydrogen generation rate.

The hydrogen generation rate versus time plot in conservative acid tests shows a slow, rising trend as more $\mathrm{Rh}$ becomes active rather than an abrupt, sharp peak close to the end of nitrite destruction. It is not known whether the nitro-Rh complex can outlast the excess acid or whether the complex is ultimately destroyed, but it is of little practical significance if the timing is long after the SME cycle is complete, and if hydrogen generation rates never exceeded a few percent of the DWPF CPC limits. These issues, however, should be taken as a warning that potential future testing using simplified model systems could behave differently than DWPF SRAT batches when the concentrations of key species are moved too far from the usual values.

The form of noble metal testing showed a slower activation of coprecipitated catalysts than comparable trimmed noble metal simulant tests at fairly high acid stoichiometry (trimmed tests had a fairly sharp hydrogen generation maximum). ${ }^{6}$ If nitrite ion is destroyed equally fast in both systems, then potentially inhibited $\mathrm{Rh}$ dissolution could lead to a reduced maximum generation rate in the coprecipitated case. For example, a reduction might be seen if $\mathrm{Rh}$ has not undergone initial dissolution prior to nitrite destruction; but perhaps it is not critical for all $\mathrm{Rh}$ to dissolve, since a significant fraction reprecipitated prior to hydrogen generation in the bead-frit Rh tests. Something of this general nature was observed during form of noble metal testing, but the shift in timing of the peak to about four hours later was a bigger difference than in maximum rate.

Nitrite ion may not have been destroyed equally fast in the trimmed and coprecipitated noble metal systems. This would also complicate comparisons of the noble metal activity. Given the current understanding of nitrite destruction, it is quite possible that nitrite was destroyed faster in the trimmed noble metal system than the coprecipitated noble metal system, since activated $\mathrm{Rh}$ and $\mathrm{Pd}$ both catalyze nitrite destruction. The trimmed $\mathrm{Rh}$ and $\mathrm{Pd}$ may have been more active early in the SRAT cycle, e.g. during nitrite destruction, then the coprecipitated Rh and Pd.

The form of noble metal tests did not have mercury and did not track nitrite ion concentrations around the time of maximum hydrogen generation, so there would be some 
value in repeating one of these comparisons with mercury included and additional sampling for nitrite. Without nitrite data, it is not possible to show that the early trimmed peak and the later coprecipitated noble metal peak were actually both driven by predominantly $\mathrm{Rh}$ catalysis at low nitrite concentration. If $\mathrm{Rh}$ does not activate sufficiently and if excess acid is present, then $\mathrm{Ru}$ catalysis will initiate after nitrite is destroyed. It is also possible that the delayed activation of $\mathrm{Rh}$ with coprecipitated noble metals may have been accompanied by a matching delay in the destruction of excess acid which permitted a comparable maximum hydrogen generation rate to be obtained four hours later into the SRAT cycle compared to trimmed noble metals.

The Rh-Ru-Hg matrix study data at constant acid showed very minimal shifts in the timing of the Rh catalyzed peak in hydrogen generation shortly after acid addition using trimmed noble metals over a wide range of concentrations (at a single acceptable, but aggressive, acid addition stoichiometry for hydrogen generation). Subtle shifts in peak timing could have been due to changing mercury concentrations that altered the rate of nitrite ion destruction. Data on nitrite ion as a function of time are not available for the form of $\mathrm{Rh}-\mathrm{Ru}-\mathrm{Hg}$ matrix testing. The onset of reflux may also be a confounding factor, since a small amount of nitrite is typically present in the condensate formed during nitrite destruction and retained in the MWWT until the start of reflux.

Statistical modeling of the matrix data on the $\mathrm{Rh}$ peak time indicated that $\mathrm{Rh}$ concentration was clearly significant to the actual timing when testing linear $\mathrm{Rh}, \mathrm{Ru}$, and $\mathrm{Hg}$ effects only. The JMP statistical software would construct a linear model containing $\mathrm{Rh}, \mathrm{Hg}$, a $\mathrm{Rh}-\mathrm{Hg}$ interaction effect, and a quadratic effect with an $\mathrm{R}^{2}$ of 0.62 when taking advantage of the fullfactorial design of the matrix. The modeling, however, has as an underlying hypothesis that the only variables are $\mathrm{Rh}, \mathrm{Ru}$, and $\mathrm{Hg}$ concentrations. There were potential small differences among the individual simulations during this period, however, such as variations in the time between end of formic acid addition and start of boiling and in the elapsed time required for dewatering. In other words, there were other potential sources of variations in the timing of the $\mathrm{Rh}$ driven peak in hydrogen generation than simply $\mathrm{Rh}, \mathrm{Ru}$, and $\mathrm{Hg}$. Consequently, this modeling result was not included in the statistical matrix report. When viewed in the broader context of what appears to be happening with nitrite destruction and Rh activation and why, however, the JMP modeling results are at least consistent with the emerging understanding.

All data to date on extent of $\mathrm{Rh}$ dissolution during hydrogen generation show that less than half of the $\mathrm{Rh}$ is in the supernate during hydrogen generation. ${ }^{9}$ Most of the data indicate less than a quarter of the $\mathrm{Rh}$ is in the supernate. Rh seems to undergo a dissolution-precipitation sequence during acid addition-nitrite ion destruction and prior to hydrogen generation. It is not yet known precisely how this sequence alters the form of $\mathrm{Rh}$ from the starting hydroxide. The form of noble metal testing showed that $\mathrm{Rh}$ continued to precipitate after the maximum hydrogen generation rate was reached, and that the concentration of dissolved $\mathrm{Rh}$ and the hydrogen generation rate were linearly correlated during the period following the maximum. As the concentration of dissolved $\mathrm{Rh}$ fell, the hydrogen generation rate fell. The hydrogen generation rate, however, did not necessarily go to zero as the soluble Rh concentration approached zero near the end of the SRAT cycle. Given the hydrogen timing, the noble 
metal controlling the hydrogen generation could have been $\mathrm{Ru}$, either by itself or in combination with $\mathrm{Rh}$.

A potential sequence for hydrogen generation by $\mathrm{Rh}$ catalysis has been constructed from the historical work combined with the recent data. It proceeds as follows:

- The $\mathrm{Rh}(\mathrm{OH})_{3}$ precipitate begins to dissolve during acid addition.

- The Rh cation collects nitrite ligands; perhaps as many as six, forming a $\mathrm{Rh}\left(\mathrm{NO}_{2}\right)_{6}{ }^{3+}$ complex.

- The Rh species catalyze nitrite ion destruction to $\mathrm{N}_{2} \mathrm{O}$ by formic acid.

- The Rh species potentially catalyzes nitrite destruction to NO by formic acid.

- Some of the catalytic Rh species may adsorb onto the insoluble solid surfaces.

- As the supernate nitrite ion concentration falls to concentrations comparable to $\mathrm{Rh}$, the equilibrium between nitrite ligands and other ligands, e.g. water, begins to permit ligand exchange through reactions such as the five step cyclical path below. ${ }^{32}$

Step one:

$\left[R h\left(\mathrm{NO}_{2}\right)_{6}\right]^{3-}+2 \mathrm{H}_{2} \mathrm{O} \leftrightarrow\left[\mathrm{Rh}\left(\mathrm{NO}_{2}\right)_{5}\left(\mathrm{H}_{2} \mathrm{O}\right)\right]^{2-}+\mathrm{NO}_{2}^{-}+\mathrm{H}_{2} \mathrm{O} \leftrightarrow\left[R h\left(\mathrm{NO}_{2}\right)_{4}\left(\mathrm{H}_{2} \mathrm{O}\right)_{2}\right]^{-}+2 \mathrm{NO}_{2}^{-}$

Step two:

$\left[\mathrm{Rh}\left(\mathrm{NO}_{2}\right)_{4}\left(\mathrm{H}_{2} \mathrm{O}\right)_{2}\right]^{-}+\mathrm{HCO}_{2}^{-} \leftrightarrow\left[R h\left(\mathrm{NO}_{2}\right)_{4}\left(\mathrm{H}_{2} \mathrm{O}\right)\left(\mathrm{HCO}_{2}\right)\right]^{2-}+\mathrm{H}_{2} \mathrm{O}$

Step three:

$\left[R h\left(\mathrm{NO}_{2}\right)_{4}\left(\mathrm{H}_{2} \mathrm{O}\right)\left(\mathrm{HCO}_{2}\right)\right]^{2-} \rightarrow\left[\mathrm{Rh}^{2}\left(\mathrm{NO}_{2}\right)_{4}\left(\mathrm{H}_{2} \mathrm{O}\right) \mathrm{H}^{2-}+\mathrm{CO}_{2}\right.$

Step four:

$\left[R h\left(\mathrm{NO}_{2}\right)_{4}\left(\mathrm{H}_{2} \mathrm{O}\right) \mathrm{H}\right]^{2-}+\mathrm{H}_{2} \mathrm{O} \rightarrow\left[\mathrm{Rh}\left(\mathrm{NO}_{2}\right)_{4}\left(\mathrm{H}_{2} \mathrm{O}\right)(\mathrm{OH})\right]^{2-}+\mathrm{H}_{2}$

Step five:

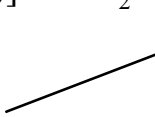

$\left.\left[\mathrm{Rh}\left(\mathrm{NO}_{2}\right)_{4}\left(\mathrm{H}_{2} \mathrm{O}\right)(\mathrm{OH})\right]^{2-}+\mathrm{HCO}_{2} \mathrm{H} \rightarrow\left[\mathrm{Rh}^{2} \mathrm{NO}_{2}\right)_{4}\left(\mathrm{H}_{2} \mathrm{O}\right)_{2}\right]^{-}+\mathrm{HCO}_{2}^{-}$

These reactions make hydrogen (step 4), consume formate ion (step 2), produce $\mathrm{CO}_{2}$ (step 3), and consume acid (step 5) that can be from any source of acidic protons. All of these effects are actually observable during SRAT processing (by gas chromatography, $\mathrm{pH}$ monitoring, and ion chromatography). The existence of nitrite ion (step 1) was confirmed during the bead-frit tests where the Rh concentration was high enough, $0.2 \mathrm{wt} \%$ in the total solids, that a comparable nitrite ion concentration $(100-1000 \mathrm{mg} / \mathrm{kg})$ could still be detected at the time of hydrogen generation. 
- As further nitrite ion destruction occurs, the nitro-Rh species in the reactions above disappear, perhaps as shown below,

$$
\begin{aligned}
& {\left[\mathrm{Rh}\left(\mathrm{NO}_{2}\right)_{4}\left(\mathrm{H}_{2} \mathrm{O}\right)_{2}\right]^{-}+\mathrm{H}_{2} \mathrm{O} \leftrightarrow\left[\mathrm{Rh}\left(\mathrm{NO}_{2}\right)_{3}\left(\mathrm{H}_{2} \mathrm{O}\right)_{3}\right]+\mathrm{NO}_{2}^{-}} \\
& {\left[\mathrm{Rh}\left(\mathrm{NO}_{2}\right)_{3}\left(\mathrm{H}_{2} \mathrm{O}\right)_{3}\right]+\mathrm{H}_{2} \mathrm{O} \leftrightarrow\left[\mathrm{Rh}\left(\mathrm{NO}_{2}\right)_{2}\left(\mathrm{H}_{2} \mathrm{O}\right)_{4}\right]^{+}+\mathrm{NO}_{2}^{-}}
\end{aligned}
$$

where the subsequent destruction of the freed up nitrite ions forces the series of sequential equilibria to the right and away from the complex(es) catalyzing hydrogen formation on the left.

- The remaining supernate $\mathrm{Rh}$ precipitates with a simultaneous reduction in catalytic activity for hydrogen generation. Conversely, formic acid may be reducing $\mathrm{Rh}$ to the element by an alternative reaction path that removes it from the supernate.

- Data taken in the Boley-Lambert study ${ }^{5}$ indicated significantly lower catalytic activity for elemental $\mathrm{Rh}$ on a commercial catalyst support than for trimmed noble metals undergoing SRAT chemistry, but they did still indicate that elemental Rh was able to produce hydrogen (a nitro-Rh complex was not required for some hydrogen generation).

- Species such as $\mathrm{Pd}, \mathrm{Ru}$, and $\mathrm{Hg}$ impact nitrite destruction kinetics. Anything that impacts nitrite destruction kinetics should also impact nitro-Rh complex catalysis to make hydrogen.

- Evidence for a Rh-Hg amalgam has not yet been found, but that does not mean that such a species does not form. If the primary $\mathrm{Rh}$ catalysis is by nitro- $\mathrm{Rh}$ complex, however, then the elemental $\mathrm{Rh}$ in the amalgam is a different form of $\mathrm{Rh}$ than the $\mathrm{Rh}^{3+}$ in the complex. Therefore, a $\mathrm{Rh}-\mathrm{Hg}$ amalgam may not matter during the early maximum hydrogen generation rates associated with $\mathrm{Rh}$. The potentially more open structure of elemental $\mathrm{Rh}$ after the $\mathrm{Hg}$ has been stripped, in other words a spongy structure (high porosity and surface area per unit volume) versus a crystalline solid (no porosity and low surface area per unit volume), however, could form a more active elemental catalyst for later in the SRAT and SME.

- Small concentrations of $\mathrm{Hg}(\sim 0.1 \mathrm{wt} \%)$ appear to be able to disrupt the chain of reactions leading to hydrogen generation in the five step reaction sequence above and to cause significantly reduced maximum hydrogen generation rates. Higher concentrations of $\mathrm{Hg}$ cause only small additional reductions. ${ }^{13}$ Reactions unrelated to nitrite destruction or amalgams may be at work. Experimental data link $\mathrm{Hg}$ to accelerated nitrite destruction kinetics, which may shorten the life cycle of the active Rh species.

- Larger acid additions accelerate nitrite destruction kinetics. The rate of nitrite destruction appears to generally be higher during acid addition than following acid 
addition. The potential benefit of accelerated nitrite destruction appears, in this case, to be outweighed by the quantity of extra formic acid available for hydrogen generation (adding more acid is not a strategy to reduce hydrogen generation by $\mathrm{Rh}$ ).

- Larger acid additions favor formic acid over formate ion. The fifth step in the above reaction scheme requires a supply of acid to reprotonate the complex and to return it to the first step. As acid is consumed, or as $\mathrm{pH}$ rises, this cycle would be expected to be retarded, resulting in decreased hydrogen generation rates (by $\mathrm{Rh}$ complexes).

- Which process controls the decline in hydrogen generation rate when sharp short duration peaks in the hydrogen generation rate are observed? It could be destruction of the complexes themselves (via nitrite destruction) or it could be the consumption of free acid that feeds the cycle and keeps it going. (Acid is also consumed destroying the nitrite ligands on the complex in addition to the destruction from hydrogen generation, so perhaps the answer is that both processes are controlled by acid consumption regardless of which is the critical step in deactivation.)

- A first attempt at deactivating the catalytic species by metering in a sodium nitrite solution demonstrated that there was a significant effect even though the nitrite concentration remained very low for quite a few hours. (This concept drives the first reaction step in the above five step scheme to the left and away from the hydrolyzed form that catalyzes hydrogen generation.) Most of the nitrite being added was being destroyed by the usual nitrite ion destruction mechanisms. Enough additional nitrite ion must have persisted, however, to alter the preferred Rh complex away from the ideal state associated with the maximum hydrogen generation rate. ${ }^{16}$ (As the nitrite concentration ultimately rose toward the end of the SRAT, hydrogen generation began to fall to zero, but the quantity of excess acid was probably also depleted by that time.)

This, then, is the present understanding of Rh catalyzed hydrogen generation in the SRAT for the nitric acid-formic acid, redox-balanced, sludge-only, flowsheet.

\subsection{CPC CATALYSIS BY RUTHENIUM}

The Rh-Ru-Hg matrix study showed that the maximum SRAT hydrogen generation rate is not always due to $\mathrm{Rh}$ catalysis. Under certain combinations of $\mathrm{Rh}-\mathrm{Ru}-\mathrm{Hg}$ and acid, the maximum generation rate can shift toward the period in the SRAT where nitrite has been destroyed (eliminating the nitro-Rh complexes). In these situations, it appears that $\mathrm{Ru}$ is controlling the magnitude of the hydrogen generation rate. The current understanding of $\mathrm{Ru}$ chemistry during the SRAT is not as advanced as that for Rh other than to note that it appears to be even more complex.

The bead-frit testing ${ }^{9}$ showed a potentially unusual dissolution-precipitation-dissolutionprecipitation sequence for $\mathrm{Ru}$ during the SRAT. The second dissolution step seemed to coincide approximately with the tail end of nitrite destruction. Simulant testing begins with $\mathrm{RuCl}_{3}$, i.e. with $\mathrm{Ru}^{3+}$. Washed simulant was believed to oxidize the $\mathrm{Ru}$ to $\mathrm{Ru}^{4+}$ prior to the 
start of the SRAT cycle. X-ray absorption spectroscopy (XAS) appears to confirm the presence of the $\mathrm{Ru}^{4+}$ species in the SRAT receipt sample. ${ }^{12}$ By the end of acid addition and prior to the end of nitrite destruction in these tests, it appeared that the $\mathrm{Ru}$ had reverted to $\mathrm{Ru}^{3+}$ presumably through formic acid reduction.

Perhaps it was the reduction reaction from $\mathrm{Ru}^{4+}$ to $\mathrm{Ru}^{3+}$ that was associated with the initial dissolution-precipitation sequence (dissolution of $\mathrm{Ru}^{4+}$ as insoluble $\mathrm{RuO}_{2}$ or $\mathrm{Ru}(\mathrm{OH})_{4}$ and formation of soluble $\mathrm{Ru}^{3+}$ or a complex with $\mathrm{Ru}$ in the same oxidation state). An alternative possibility is that a nitro-Ru complex formed that was destroyed as nitrite was destroyed, and that the nitro-Ru complex was not an active catalyst for hydrogen generation.

The identity of the insoluble $\mathrm{Ru}^{3+}$ form is presently unknown. SRNL data and University of Georgia data both indicate no hydrogen generation from $\mathrm{Ru}$ in the presence of nitrite ion (at least at several times more nitrite ion than $\mathrm{Ru}$ by molar concentration). The eventual destruction of nitrite may liberate the $\mathrm{Ru}^{3+}$ from an inactive complex form and allow it to take on an as yet unidentified active form for hydrogen generation.

So far, the data on $\mathrm{Ru}$ indicate that, all else being equal, more $\mathrm{Ru}$ has generally correlated to greater maximum hydrogen generation rates in the time period dominated by $\mathrm{Ru}$ catalysis. Data include the $\mathrm{Rh}-\mathrm{Ru}-\mathrm{Hg}$ matrix study and the bead-frit testing at two initial $\mathrm{Ru}$ concentrations. $^{9,13}$ The form of noble metal testing trimmed all noble metals at $100 \%, 65 \%$, $40 \%$ and $20 \%$ of nominal in four tests at equal acid addition. The maximum hydrogen generation rate fell as noble metal concentrations fell from $65 \%$ to $40 \%$ to $20 \%$, but the maximum hydrogen generation rate also moved to later times until the peak for $20 \%$ nominal noble metals was near the end of the SRAT cycle. The maxima at $100 \%$ and $65 \%$ may well have been due to $\mathrm{Rh}$ rather than $\mathrm{Ru}$, since they occurred in the first few hours after acid addition. It has not been proven conclusively that the later maxima in this series were due to $\mathrm{Ru}$ although the timing suggests that they may have been. Also, the declining hydrogen generation rate correlated with either the declining $\mathrm{Rh}$ concentration or the declining $\mathrm{Ru}$ concentration.

It remains possible that a fraction of the $\mathrm{Rh}$ could possess heightened activity using the last remaining nitrite ions to sustain a small concentration of the proposed complex. The resulting free nitrite ion concentration would be too low to inhibit $\mathrm{Ru}$, which is typically present at three to four moles $\mathrm{Ru}$ per mole $\mathrm{Rh}$. At least some fraction of $\mathrm{Ru}$ can then become active (uninhibited by nitrite) in parallel with the remaining nitro-Rh complex rather than in parallel with the subsequent, lower activity form of $\mathrm{Rh}$, e.g. elemental $\mathrm{Rh}$ or some other species.

$\mathrm{Ru}$ single noble metal catalysis rose to a maximum hydrogen generation rate much more slowly than $\mathrm{Rh}$ under comparable conditions in the bead-frit tests. ${ }^{9}$ The increase in hydrogen generation rate seemed to track the second dissolution portion of the dissolutionprecipitation-dissolution-precipitation sequence. The hydrogen generation rate then began to fall during the final precipitation step of the sequence. The second precipitation of $\mathrm{Ru}$, however, seems to be fairly slow and seldom goes to completion during the SME cycle. This suggests that there may be a dynamic equilibrium between the soluble $\mathrm{Ru}$ species and an 
adsorbed $\mathrm{Ru}$ species bound to the insoluble solids. Data from both the form of noble metal testing and the bead-frit testing showed a linear correlation between the falling hydrogen generation rate and the declining Ru solubility. Data from the $\mathrm{Rh}-\mathrm{Ru}-\mathrm{Hg}$ matrix also showed that the maximum hydrogen generation rate was nearly proportional to the $\mathrm{Ru}$ concentration when $\mathrm{Ru}$ catalysis dominated over Rh catalysis.

The XAS data on SRAT samples taken after acid addition showed virtually no change in oxidation state (possibly a weak indication was noted that a small fraction of the Ru was reducing to oxidation state zero, but the spectrum wave form appeared to be dominated by the $\mathrm{Ru}^{3+}$ shape, not the $\mathrm{Ru}^{0}$ shape). ${ }^{12}$ The reducing power of the SRAT supernate in the last few hours of reflux after significant catalytic formic acid destruction may be non-existent in the bead-frit tests, and that situation may not necessarily be the case for all SRAT cycles. New data from the oxidation-reduction probe (ORP) during boiling indicates a significant shift toward a less reducing-more oxidizing supernate at the time of the Rh-driven peak in hydrogen generation rate. This shift has been seen five times out of five opportunities. If the ORP data are a reliable indicator of the reducing potential of the SRAT, then Rh should reduce to the element earlier in the SRAT cycle rather than later. The reaction(s) driving the loss in reductive potential are still under investigation.

The physical process responsible for removing $\mathrm{Ru}$ from the supernate following the second dissolution step in the observed sequence appears to be either reactant or equilibrium limited, since $\mathrm{Ru}$ never fully drops out of solution even when the data base is extended to the end of the SME cycle. Consequently, hydrogen generation persists through the SME cycle. Hydrogen generation continues in $\mathrm{Ru}$ tests at a fairly steady rate if an obvious peak has already occurred earlier (triggering the final precipitation step), or else is often observed to be on a generally upward trend with time at the end of the SRAT and/or into the SME cycle (apparently still in the second dissolution step rather than the second precipitation step).

A test was performed where sodium nitrite solution was metered into the SRAT following acid addition. ${ }^{16}$ A small level of nitrite ion was apparently sustained initially, and ultimately the nitrite ion concentration began rising as excess acid was consumed. The data from this test do not show evidence that the $\mathrm{Ru}$ ever became catalytically active for hydrogen generation.

Mercury impacted the results in the mid-SRAT through end of SME period during the RhRu-Hg matrix study. ${ }^{13}$ Higher initial $\mathrm{Hg}$ tended to delay the maximum hydrogen generation rate associated with $\mathrm{Ru}$, but the maximum hydrogen generation rate also seemed to increase with increasing Hg. This increase may have been due to reduced formic acid destruction prior to $\mathrm{Ru}$ activation rather than to promotion of $\mathrm{Ru}$ catalytic activity by $\mathrm{Hg}$. Constant $\mathrm{Rh}-$ $\mathrm{Ru}$ pairs in the $\mathrm{Rh}-\mathrm{Ru}-\mathrm{Hg}$ study tended to have a cross-over point where the high initial $\mathrm{Hg}$ run went from a lower to a higher hydrogen generation rate than the matching low initial $\mathrm{Hg}$ run. ${ }^{13}$ The cross-over occurred sooner when the noble metal concentrations were relatively greater (high Rh-high Ru crossed in the SRAT, low Rh-low Ru crossed in the SME).

The bead-frit matching test with $\mathrm{Ru}$ and $\mathrm{Hg}$ had hydrogen generation initiate about an hour earlier when $\mathrm{Hg}$ was added, but this did not produce a significant change in the timing of the 
maximum rate. This is consistent with $\mathrm{Hg}$ accelerating nitrite destruction, and nitrite destruction being a prerequisite for $\mathrm{Ru}$ catalyzed hydrogen generation. The fact that the maximum generation rate did not occur sooner with $\mathrm{Hg}$ present (and accelerated nitrite destruction) may imply that the $\mathrm{Ru}$ activation step for catalytic hydrogen generation does not involve either $\mathrm{Hg}$ or nitrite directly.

\subsection{DETERMINATION AND CONTROL OF EXCESS ACID}

While uncertainty exists in the acid calculation, sludge batches $1 \mathrm{~A}, 1 \mathrm{~B}, 2,3$, and 4 (SB1ASB4) were processed successfully by DWPF using empirical correction factors, and sludge batch 5 (SB5) is being processed successfully now. A single unique correction factor was used for each sludge batch except SB2, where the factor was gradually increased to deal with air entrainment-rheology issues in the slurry. The uncertainties in the acid equation were compensated for by establishing an empirical correction factor in the Shielded Cells and running a series of nearly identical SRAT batches with a single factor.

Future sludge batches are likely to be more variable in acid requirement as changing quantities of salt waste processing streams are introduced to individual SRAT batches. Consequently, the need for more accurate stoichiometric acid equations could become an issue in the effort to control excess acid (and hydrogen thereby) in the SRAT. Fortunately, progress has been made in this area. The new equations are undergoing a validation process at SRNL prior to recommending a change at DWPF.

Excess formic acid has been identified as the reactant during noble metal catalytic hydrogen generation. Nitric acid is a strong acid, while formic acid is a weak acid. After both acids have been added to the SRAT slurry, nitric acid has been converted to dissolved sodium and nitrate ions. Molecular formic acid and formate ion concentrations control the hydrogen ion concentration in the system. The distribution is governed by the equilibrium constant for formic acid dissociation plus any applicable equilibria between formate ion and other cations. Adding more nitric acid and less formic acid does not change the nature of the governing equilibrium relationships (that the acidity is controlled by formic acid not nitric acid), but it does reduce the total formate ion concentration which allows for an increase in the $\mathrm{H}^{+}$ concentration (reduces the $\mathrm{pH}$ ). In addition to binding acid protons on the formate ion, the potential exists to have some of the unreacted acid protons temporarily tied up as molecular nitrous acid, $\mathrm{HNO}_{2}$, and/or acidic bioxalate ion $\left(\mathrm{C}_{2} \mathrm{O}_{4} \mathrm{H}^{+}\right)$.

Nitrous acid and nitrite ion are typically destroyed in the SRAT cycle under the current operating philosophy, which is to allow hydrogen generation to occur in the SRAT, bring it under control as necessary, and then transfer the slurry forward to the SME (which has a smaller air purge to dilute evolved hydrogen). Formate, oxalate, and nitrite are the three principal weak acid anions. Oxalate concentrations are typically fairly low, and nitrite is being destroyed. Therefore, most of the excess acid protons near the end of acid addition and later are associated with formate ion. Catalytic attack on formic acid produces hydrogen and carbon dioxide (primarily; although it is possible to form carbon monoxide and water under certain conditions). 
The current strategy for controlling hydrogen generation is to limit the amount of excess acid that is added per SRAT cycle to the sludge slurry. This control is accomplished by performing a calculation of the acid requirement based on analytical measurements of the SRAT receipt slurry. Successful processing, however, requires more acid than that calculated by the current equation. The adjustment is accomplished by using a multiplicative correction factor. DWPF SRAT processing has typically been performed at $125-175 \%$ of the calculated stoichiometric acid requirement.

Complicating the above approach are the measurements of the five primary inputs to the current stoichiometric acid equation. These include a titration of the slurry to $\mathrm{pH} 7$ to determine the equivalent $\mathrm{NaOH}$ content (base equivalents) and a measurement of the total inorganic carbon (TIC) of the slurry, which is taken as the carbonate ion concentration. Alkali and alkaline earth carbonates are generally converted by acid to $\mathrm{CO}_{2}$ and water during SRAT processing. The DWPF titration is performed after a 20:1 to 25:1 dilution with water. Results obtained with titrations of undiluted slurry have been as much as $5-15 \%$ different. The SRAT acid addition period resembles an undiluted slurry titration. Differences of 5-15\% are not huge, but the titrated base equivalents term is typically the largest contributor in the stoichiometric acid calculation.

The accurate measurement of slurry TIC has proven to be more challenging than the measurement of base equivalents, and the analytical results can typically be considered fairly uncertain. In addition, soluble sodium carbonate is partially titrated during the measurement of equivalent base and gets counted twice. The other three inputs to the current stoichiometric acid equation are total slurry $\mathrm{Mn}, \mathrm{Hg}$, and nitrite ion. The contribution of $\mathrm{Hg}$ to the total stoichiometric acid is generally fairly insignificant. The Mn and nitrite ion terms are probably measured to within an accuracy of $\pm 10 \%$ or better.

There is additional uncertainty in the current calculation of the actual stoichiometric acid demand beyond that related to measurement uncertainties of inputs like base equivalents and slurry TIC. This uncertainty is apparent in the magnitude of the empirical correction factors. The uncertainty can translate into uncertainty with respect to how much excess acid is being added to potentially fuel catalytic hydrogen generation. Therefore, one aspect of the 20072009 catalytic hydrogen generation program has been to seek a more complete description of acid consumption. The goal has been to produce a more accurate equation to calculate the stoichiometric acid requirement and consequently to bring the multiplicative correction factor closer to $100 \%$.

Two complementary approaches were taken in the past two years with respect to creating a new stoichiometric acid equation. The first approach was to evolve the current DWPF stoichiometric acid equation into an improved second generation equation - replace slurry TIC with terms for supernate TIC and calcium and magnesium, and modify coefficients on certain other terms to improve accuracy. Measurement of dissolved TIC in a homogeneous sample is arguably simpler and more accurate than the measurement of slurry TIC.

The second approach was to look at the reactive cations in the sludge. Insoluble cations are primarily present as hydroxides, hydrous oxides, and carbonates that consume acid in a 
predictable fashion when dissolved. The soluble species at the start of the SRAT are due primarily to sodium plus charge balancing anions (hydroxide, nitrite, nitrate, sulfate, carbonate, oxalate, fluoride, chloride, aluminate, etc.) The second new stoichiometric equation sums the reactive insoluble cations plus sodium and then reduces the result by taking credit for the concentrations of the stable anions, such as nitrate, sulfate, fluoride, and chloride, which do not change during acid addition.

Preliminary approximate comparisons of the current and new acid equations show that the second generation equation and cation-based equation tend to respond similarly to changing sludge composition, but both respond differently from the current DWPF stoichiometric acid equation. ${ }^{17}$ Both new equations generally produce larger totals for the stoichiometric acid requirement than the current equation when applied to previous sludge batch compositions. Consequently, the empirical correction factors needed by the new equations tend to be closer to $100 \%$ on average. The preliminary comparisons have been approximate, however, because the supernate TIC has had to be estimated from the slurry TIC which was not routinely measured in the past. It is seen as encouraging that the two new equations are responding similarly given that they are fundamentally different in approach. It is also encouraging that the empirical correction factors have shifted closer to $100 \%$ with the new equations. 


\subsection{CONCLUSIONS}

A broad program of DWPF-related activities over the past two years has provided a variety of data that was used to improve the understanding of catalytic hydrogen generation, noble metal chemistry, and general SRAT chemistry and acid consumption. The result has been a considerable advance in the understanding of noble metal catalyzed hydrogen generation in the SRAT. In parallel with the progress in understanding the noble metals has been a matching level of progress in understanding the reactions that consume acid during the SRAT cycle. New approaches to calculating the stoichiometric acid requirement for the SRAT are well into the development process.

Rhodium appears to become most active for hydrogen as the nitrite ion concentration becomes low (within a factor of ten of the $\mathrm{Rh}$ concentration). Prior to hydrogen generation, $\mathrm{Rh}$ is definitely active for nitrite destruction to $\mathrm{N}_{2} \mathrm{O}$ and potentially active for nitrite to NO conversion. These reactions are all consistent with the existence of a nitro-Rh complex catalyst. Significant $\mathrm{Rh}$ is found in the supernate during nitrite destruction, but as nitrite begins to drop to low levels the $\mathrm{Rh}$ moves into the insoluble solids phase and hydrogen generation begins. The movement from supernate to insoluble solids may signal a change in the nature of the Rh complex as indicated by the reaction schemes in Section 4.1. The complex may be a hexa-nitro Rh complex during nitrite destruction that transitions to a lower number of nitro groups as nitrite is destroyed. Rather than water as one of the ligands as indicated in the reaction scheme, the Rh may be binding to some surface sites on the insoluble solids using one or more of the bonds previously used by nitrite ligands. The sudden sharp increases and decreases in hydrogen generation near the end or shortly after acid addition in past runs appear to correlate to the activation and deactivation of a nitro-Rh species, since nitrite destruction appears to both activate and (at least partially) deactivate Rh as a catalyst for hydrogen generation.

Ruthenium does not appear to activate for hydrogen until nitrite destruction is nearly complete (perhaps less nitrite than $\mathrm{Ru}$ in the system). The slow activation of the $\mathrm{Ru}$, as inferred from the slow rate of increase in hydrogen generation that occurs after initiation, may imply that some species (perhaps $\mathrm{Ru}$ itself) has some bound nitrite on it that is still slowly being destroyed and preventing $\mathrm{Ru}$ from reaching its full catalytic activity. Alternatively, the kinetics of either destruction of the residual nitrite and/or formation of the active $\mathrm{Ru}$ species could be rate limiting steps that must be given time to occur before $\mathrm{Ru}$ reaches its maximum catalytic activity for hydrogen generation. Subsequent to achieving this maximum activity (which may not necessarily occur within the time frame of a SRAT/SME cycle), Ru can undergo a process which reduces its supernate concentration to a low, but apparently pseudo-steady state nonzero value. Hydrogen generation rates generally fall linearly as the supernate $\mathrm{Ru}$ concentration falls. The rate then approximately stabilizes and shows no signs of further deactivation of the $\mathrm{Ru}$ catalyst for hydrogen generation which can persist at fairly stable levels until the end of SRAT/SME simulations. 
Mercury has a role in catalytic hydrogen generation. Two potentially distinct roles have been identified. The most dramatic effect of $\mathrm{Hg}$ on hydrogen generation occurs between runs with and without any $\mathrm{Hg}$. There is a major inhibiting effect when a small amount of $\mathrm{Hg}$ is present. The Rh-Ru-Hg matrix study showed much smaller inhibiting effects as $\mathrm{Hg}$ increased from 0.5 to 1.5 to $2.5 \mathrm{wt} \%$ in the total solids of the starting sludge. The next most readily identified role for $\mathrm{Hg}$ is the impact it has on accelerating $\mathrm{NO}$ production from nitrite ion. This reaction shifts the time that the ideal concentration of nitrite relative to Rh occurs, and consequently causes the most active nitro-Rh species to form sooner. The potential consequences of this shift in timing are expected to be a function of other factors such as amount of excess acid, Rh concentration, etc.

$\mathrm{Ru}$, rather than $\mathrm{Rh}$, is probably primarily responsible for the hydrogen generation in the SME cycle when hydrogen concentrations are high enough to be noteworthy. Hydrogen generation rates at the start of the SME cycle are often fairly similar to those at the end of the SRAT cycle (in the absence of dilution by SME heels) when canister dewatering is simulated. Hydrogen generation can be promoted relative to the SRAT if the SME starts with a frit-water-formic acid addition instead of a canister decontamination water addition.

Palladium is an active catalyst, but it activates during (or prior to) nitrite destruction to promote $\mathrm{N}_{2} \mathrm{O}$ formation followed by a very small amount of hydrogen. It then appears to deactivate. Data to date indicate that $\mathrm{Pd}$ should not be a species of primary concern relative to $\mathrm{Rh}$ and $\mathrm{Ru}$. It not only showed no evidence of being more active ( $\mathrm{Rh}$ and $\mathrm{Pd}$ at $0.2 \mathrm{wt} \%$ produced comparable enhancements in $\mathrm{N}_{2} \mathrm{O}$ production), but $\mathrm{Pd}$ is almost always present at less than a quarter of the Rh concentration. Ag did not appear to ever become active for hydrogen generation. Data from two tests spiked with silver were comparable to the data from two tests with no noble metals.

Supporting work has included a program to better define SRAT chemistry and acid consumption. Improved control of excess acid is improved control of the potential to generate catalytic hydrogen during the SRAT cycle. This program has led to two new stoichiometric acid equations that predict acid demand better than the current DWPF equation. Refinement work on these two equations is in progress. The goal is to have them ready for implementation in SB6. 


\subsection{FUTURE WORK}

While much progress has been made on understanding catalytic hydrogen generation and on improved methods to control excess acid, there are still some potential blind spots in the understanding of noble metal catalysis. It appears to be unlikely that the existence of the postulated nitro-rhodium complex can be proven in actual SRAT samples, either radioactive or simulant, with current technology (XAS is insensitive to low atomic weight atoms such as $\mathrm{N}$ and $\mathrm{O}$ ). The noble metal dissolution data were not conclusive as to whether the postulated nitro-Rh complex was in the supernate or was adsorbed onto the surface of the insoluble solids. In practical terms it may not matter, since both forms are still in the SRAT. Even less is known about the active form of the $\mathrm{Ru}$ catalyst (other than that it is presumably not based on nitrite ligands). If ligand complexes are the most catalytically active forms of $\mathrm{Rh}$ and $\mathrm{Ru}$, then it is possible that the presence of other anion ligands could alter the activity or even threaten the existence of the catalytic complexes. Systematic testing for the potential interferences of other anion ligands on catalytic activity has not been done for the SRAT system.

If the catalytically active noble metal complexes are adsorbed onto the insoluble solids, then the composition variations of the main insoluble solids may affect catalytic activity. The sludge matrix study is underway with many goals including identifying the effects of major changes in the insoluble solids on the stoichiometric acid requirement and hydrogen generation. This study is designed to be performed at essentially constant initial supernate concentration, so it will not reveal whether or not the anion distribution might impact the active ligand-based complexes.

Recent small-scale tests at the University of Idaho have shown the potential for mesoporous silica containing nitrogen rich ligands to sequester the $\mathrm{Rh}$ and $\mathrm{Ru}$ from the SRAT during their periods of solubility and greatly reduce their catalytic activity. Demonstrations of this alternative approach to controlling hydrogen generation are pending.

Alternate reductant flowsheet work has shown that the quantity of formic acid required could be reduced by using a second reducing acid, such as glycolic acid, as a substitute. Formic acid and glycolic acid would be put into a solution and fed to the SRAT like 90\% formic acid is now. It is hoped that such a strategy would still permit mercury reduction and stripping to occur in the SRAT cycle. 
SRNL-STI-2009-00214, REVISION 0

\subsection{REFERENCES}

1 Plodinec, M. J., Report of the Hydrogen Generation Review Panel - Review of Hydrogen Generation in the DWPF. March 15, 2007.

${ }^{2}$ HLW-DWPF-TTR-2007-0016, Catalytic Hydrogen Generation Program, B. A. Davis, March 8, 2007.

${ }^{3}$ Koopman, D. C., Task Technical and Quality Assurance Plan - Catalytic Hydrogen Generation Program. WSRC-RP-2007-00338, SRNL, Aiken, SC, 29808 (April 2007).

${ }^{4}$ Koopman, D. C., Review of Hydrogen Generation in the Defense Waste Processing Facility (DWPF) Chemical Processing Cell, WSRC-TR-2002-00034, Savannah River Technology Center, Aiken, SC, 29808 (December 2004).

${ }^{5}$ Koopman, D. C., D. P. Lambert, and M. A. Baich, Review of Catalytic Hydrogen Generation in the DWPF Chemical Processing Cell, Part II, WSRC-TR-2005-00206, Savannah River Technology Center, Aiken, SC, 29808 (August 2005).

${ }^{6}$ Koopman, D. C., DWPF Hydrogen Generation Study: Form of Noble Metal SRAT Testing, WSRCTR-2005-00286, SRNL, Aiken, SC, 29808 (July 2005).

${ }^{7}$ Koopman, D. C., DWPF Hydrogen Generation Study: Phase II Form of Noble Metal Testing, WSRC-TR-2005-00420, SRNL, Aiken, SC, 29808 (December 2005).

${ }^{8}$ Koopman, D. C., Preparation, Characterization, and Preliminary SRAT/SME Testing of a Simulant for the Hydrogen and Rheology Modifiers Program. SRNL-PSE-2007-00191, SRNL, Aiken, SC, 29808 (September 2007).

${ }^{9}$ Koopman, D. C., Noble Metal Chemistry and Hydrogen Generation During Simulated DWPF Melter Feed Preparation, WSRC-STI-2008-00002, SRNL, Aiken, SC, 29808 (June 2008).

${ }^{10}$ Koopman, D. C., D. R. Best, and B. R. Pickenheim, SRAT Chemistry and Acid Consumption During Simulated DWPF Melter Feed Preparation, WSRC-STI-2008-00131, SRNL, Aiken, SC, 29808 (December 2008).

${ }^{11}$ Koopman, D. C., Data Summary for Bead-Frit Matching Test with Rh and Hg, SRNL-L3100-200900xyz, SRNL, Aiken, SC, 29808 (February 2009).

${ }^{12}$ Fox, E. B. and B. R. Pickenheim, Speciation of Ru and Hg During Simulated Nuclear Waste Processing, SRNL-MST-2008-00151, SRNL, Aiken, SC 29808 (July 2008).

${ }^{13}$ Koopman, D. C., Catalytic Interactions of Rhodium, Ruthenium, and Mercury during Simulated DWPF CPC Processing with Hydrogen Generation, WSRC-STI-2008-00235. SRNL, Aiken, SC, 29808 (July 2008).

${ }^{14}$ Koopman, D. C. and T. B. Edwards, Statistical Evaluation of Processing Data from the Rh-Ru-Hg Matrix Study, SRNL-STI-2009-00084, SRNL, Aiken, SC, 29808 (February 2009). 
${ }^{15}$ Koopman, D. C., Preliminary Evaluation of Two Alternative Flowsheet Runs, SRNL-L3100-200800112, SRNL, Aiken, SC, 29808 (November 2008).

${ }^{16}$ Koopman, D. C., Deactivation of Catalytic Hydrogen Generation via Sodium Nitrite Addition, SRNL-L3100-2009-00007, SRNL, Aiken, SC, 29808 (January 2009).

${ }^{17}$ Koopman, D. C., Comparison of Two Proposed SRAT Acid Equations with Shielded Cells Data, SRNL-L3100-2008-00008, SRNL, Aiken, SC, 29808 (November 2008).

${ }^{18}$ Lambert, D. P., M. E. Stone, B. R. Pickenheim, D. R. Best, D. C. Koopman, Sludge Batch 5 Simulant Flowsheet Studies, SRNS-STI-2008-00024, Aiken, SC, 29808 (October 2008).

${ }^{19}$ Koopman, D. C., Evaluation of Potential Foaminess in Sludge Batch 5 Simulants, SRNL-L31002008-00001, SRNL, Aiken, SC, 29808 (September 2008).

${ }^{20}$ Koopman, D. C., T. B. Edwards, and M. D. Joner, Summary of Findings Based on Statistical Analyses of a SRAT-SME Database, SRNL-PSE-2007-00207, SRNL, Aiken, SC, 29808 (October 2007).

${ }^{21}$ Koopman, D. C., C. M. Jantzen, and T. B. Edwards, Acid Addition Stoichiometry for Sludge Batch 3 Processing in the Defense Waste Processing Facility, WSRC-TR-2003-00118, SRTC, Aiken, SC, 29808 (February 2003).

${ }^{22}$ Baich, M. A., C. C. Herman, D. R. Best, M. F. Williams, and E. K. Hansen, Sludge Batch 4 Initial Simulant Flowsheet Studies: Phase I SRAT Results, WSRC-TR-2005-00194, SRNL, Aiken, SC 29808 (June 2005).

${ }^{23}$ Koopman, D. C. and M. A. Baich, Effect of Mercury-Noble Metal Interactions on SRAT Processing of SB3 Simulants. WSRC-TR-2004-00548, SRNL, Aiken, SC 29808 (December 2004).

${ }^{24}$ Bibler, N. E., T. L. Fellinger, and D. T. Hobbs, Technetium-99 Behavior in Savannah River High Level Waste Sludges During Waste Processing, 2006 Waste Management Conference presentation, SRS, Aiken, SC, 29808 (2/26-3/2/2006).

${ }^{25}$ Koopman, D. C. and C. C. Herman, Noble Metal Catalyzed $\mathrm{H}_{2}$ in the Defense Waste Processing Facility, SRNL-PSE-2006-00290, SRNL, Aiken, SC, 29808 (December 2006).

${ }^{26}$ Pickenheim, B. R., J. M. Pareizs, C. J. Bannochie, H. M. Ajo, S. H. Reboul, Data from the SRNL Shielded Cells Demonstration of the DWPF SRAT Using SB5 Tank 1 Qualification Sample, SRNLPSE-2008-001057, SRNL, Aiken, SC, 29808 (July 2008).

${ }^{27}$ Herman, C. C., T. B. Edwards, D. C. Koopman, D. R. Best, J. C. George, and M. F. Williams, Data Summary from Sludge Batch 3 Simulant SRAT Runs to Evaluate Impacts of Noble Metals Mass and Coal Size, Mass, and Treatment, SRT-GPD-2002-00121, SRS, Aiken, SC, 29808 (November, 2002).

${ }^{28}$ Baich, M. A., D. R. Best, M. E. Stone, and M. F. Williams, Sludge Batch 2-3 Blend Flowsheet Simulations: Process Variability Study, WSRC-TR-2004-00225, SRNL, Aiken, SC 29808 (May 2004). 
${ }^{29}$ Koopman, D. C., J. M. Pareizs, D. P. Lambert, and C. J. Bannochie, Sludge Batch 4 Follow-up Qualification Studies to Evaluate Hydrogen Generation, WSRC-STI-2007-00212, SRNL, Aiken, SC, 29808 (June 2007).

${ }^{30}$ Newell, J. D., Results of Experiments Performed by University of Idaho Using Mesoporous Silica for the Removal of Rhodium and Ruthenium from Simulated Waste, SRNL-2008-L3100-00084, SRNL, Aiken, SC, 29808 (March 2009).

${ }^{31}$ Lambert, D. P., C. S. Boley, and J. R. Zamecnik, Alternative Tank 51 Sludge-Only Process Development for the Defense Waste Processing Facility (DWPF), WSRC-RP-97-40, Rev. 1, SRS, Aiken, SC, 29808 (March, 1997).

${ }^{32}$ King, R. B. and N. K. Bhattacharyya, Catalytic reactions of formate - 4. A nitrite-promoted rhodium (III) catalyst for hydrogen generation from formic acid in aqueous solution. Inorganica Chimica Acta, 237, 65-69 (1995), Elsevier. 


\section{Distribution:}

J. C. Griffin, 773-A

S. L. Marra, 773-A

C. C. Herman, 999-W

A. B. Barnes, 999-W

D. A. Crowley, 773-43A

S. D. Fink, 773-A

C. W. Gardner, 773-A

B. J. Giddings, 786-5A

F. M. Pennebaker, 773-42A

D. J. McCabe, 773-42A

J. E. Occhipinti, 704-S

E. W. Holtzscheiter, 704-15S

T. L. Fellinger, 704-26S

J. M. Bricker, 704-27S

R. T. McNew, 704-27S

D. C. Sherburne, 704-S

J. F. Iaukea, 704-30S

J. W. Ray, 704-S

H. H. Elder, 704-24S

H. B. Shah, 766-H

J. M. Gillam, 766-H

D. D. Larsen, 766-H

C. J. Bannochie, 773-42A

D. K. Peeler, 999-W

N. E. Bibler, 773-A

R. E. Eibling, 999-W

M. E. Stone, 999-W

D. P. Lambert, 999-W

B. R. Pickenheim, 999-W

A. I. Fernandez, 999-W

J. D. Newell, 999-W

J. M. Pareizs, 773-A

S. H. Reboul, 773-42A

A. S. Choi, 773-42A 